\title{
Homologs of Caenorhabditis elegans Chemosensory Genes Have Roles in Behavior and Chemotaxis in the Root-Knot Nematode Meloidogyne incognita
}

\author{
Tagginahalli N. Shivakumara, ${ }^{1}$ Tushar K. Dutta, ${ }^{1}$ Sonam Chaudhary, ${ }^{1}$ Stephan H. von Reuss, ${ }^{2}$ \\ Valerie M. Williamson, ${ }^{3}$ and Uma Rao ${ }^{1,+}$ \\ ${ }^{1}$ Division of Nematology, ICAR-Indian Agricultural Research Institute, New Delhi 110012, India \\ ${ }^{2}$ Institute of Chemistry, University of Neuchâtel, Neuchâtel, Avenue de Bellevaux 51, Switzerland \\ ${ }^{3}$ Department of Plant Pathology, University of California, Davis, CA 95616, U.S.A.
}

Accepted 10 February 2019.

\begin{abstract}
Nematode chemosensation is a vital component of their hostseeking behavior. The globally important phytonematode Meloidogyne incognita perceives and responds (via sensory organs such as amphids and phasmids) differentially to various chemical cues emanating from the rhizosphere during the course of host finding. However, compared with the freeliving worm Caenorhabditis elegans, the molecular intricacies behind the plant nematode chemotaxis are a yet-unexploited territory. In the present study, four putative chemosensory genes of $M$. incognita, namely, Mi-odr-1, Mi-odr-3, Mi-tax-2, and Mi-tax-4 were molecularly characterized. Mi-odr-1 mRNA was found to be expressed in the cell bodies of amphidial neurons and phasmids of $M$. incognita. Mi-odr-1, Mi-odr-3, Mi-tax-2, and Mi-tax-4 transcripts were highly expressed in early life stages of $M$. incognita, consistent with a role of these genes in host recognition. Functional characterization of Mi-odr-1, Mi-odr-3, Mi-tax-2, and Mi-tax-4 via RNA interference revealed behavioral defects in $M$. incognita and perturbed attraction to host roots in Pluronic gel medium. Knockdown of Mi-odr-1, Mi-odr-3, Mi-tax-2, and Mitax-4 resulted in defective chemotaxis of $M$. incognita to various volatile compounds (alcohol, ketone, aromatic compound, ester, thiazole, pyrazine), nonvolatiles of plant origin (carbohydrate, phytohormone, organic acid, amino acid, phenolic), and host root exudates in an agar-Pluronic gelbased assay plate. In addition, ascaroside-mediated signaling was impeded by downregulation of chemosensory genes. This new information that behavioral response in $M$. incognita is modulated by specific olfactory genes can be extended to understand chemotaxis in other nematodes.
\end{abstract}

Keywords: nematode-plant interactions

${ }^{\dagger}$ Corresponding author: U. Rao; umarao@iari.res.in

Funding: This work was funded by the Department of Biotechnology, Ministry of Science and Technology grant BT/PR5908/AGR/36/727/2012.

*The $\boldsymbol{e}$-Xtra logo stands for "electronic extra" and indicates that nine supplementary figures and two supplementary tables are published online.

The author(s) declare no conflict of interest.

๑) 2019 The American Phytopathological Society
Plant-parasitic nematodes (PPNs) cause an estimated annual crop yield loss of $\$ 173$ billion globally (Elling 2013). The rootknot nematode (RKN) (Meloidogyne spp.), an obligate biotroph, has been ranked as number one in importance among PPNs, due to the immensity of damage that this group inflicts on a wide range of agri- and horticultural crops (Jones et al. 2013). Immediately after hatching, second stage juveniles (J2s) of RKN must locate and invade a host root and establish a complex host-parasite relationship via the formation of specialized feeding cells, referred to as giant cells, in host plants. These giant cells serve as a constant source of nourishment for the subsequent sedentary life stages of the developing parasite (Palomares-Rius et al. 2017).

Chemosensation is an important sensory modality for PPNs that enables them to respond to chemical cues of host origin starting from their migration in soil to establishment of a suitable feeding site in host tissue (Curtis 2008; Perry 2005; Reynolds et al. 2011). The free-living nematode Caenorhabditis elegans perceives environmental cues via its chemosensory organs, including two bilaterally symmetrical amphids in its head and two pore-like phasmids in its tail (Hilliard et al. 2002). PPNs share the conserved positional sensory neuroanatomy with C. elegans (Perry 1996; Rengarajan and Hallem 2016). The ability of parasitic nematodes to chemo-orientate using a combination of head and tail chemosensory neurons is vital for their survival and is essential for detecting host root exudates, food stimulants, food deterrents, and sex pheromones.

Understanding the molecular basis of PPN chemoreception may reveal targets for genetic or chemical intervention. Perturbation of PPN chemotaxis by affecting their ability to detect and discriminate the host stimulus presents a novel nematode management strategy (Curtis 2008; Perry 1996). However, in comparison with chemosensory gene repertoire of $C$. elegans, PPN olfactory genes are yet to be functionally characterized. Use of genetic transformation methods such as laser ablation and microinjection has aided in identification of functional neural circuits in C. elegans (Rengarajan and Hallem 2016). However, due to their small size and obligate parasitic nature, PPNs are not amenable to these tools. The use of reversegenetics tools such as RNA interference (RNAi) has facilitated the functional validation of a number of parasitic candidate genes in PPNs (Dutta et al. 2015; Lilley et al. 2012).

Using loss-of-function mutants, a series of genes have been identified to be vital for C. elegans chemosensation (Bargmann and Mori 1997; Bargmann et al. 1993). The odr-1 gene of 
C. elegans encodes a membrane-bound guanylyl cyclase (GCY), an effector enzyme that produces the secondary messenger (cGMP) via heterotrimeric $G$ proteins (Colbert and Bargmann 1995; L'Etoile and Bargmann 2000). The odr-10 gene of $C$. elegans encodes a seven-transmembrane chemoreceptor protein (Sengupta et al. 1996). The odr-3 gene of C. elegans is a $\mathrm{G} \alpha$ protein that regulates cyclic nucleotide production or degradation (Roayaie et al. 1998). The heteromeric TAX-2/TAX-4 cyclic nucleotide-gated cation channel is necessary for downstream $G$ protein-mediated signaling (Coburn and Bargmann 1996). Mutations in these individual genes led to the selective loss of $C$. elegans chemotaxis to both water-soluble chemicals and volatiles.

Although in an earlier study, GCY genes HG- $g c y-1$, HG- $g c y-$ 2, and HG-gcy-3 were cloned from a PPN, Heterodera glycines, and expression patterns of HG-gcy-1 and HG-gcy-2 were localized in nerve ring, amphid, and tail neurons of nematodes, they were not functionally characterized (Yan and Davis 2002). In view of this, in the present study, homologs of known chemosensory genes (odr-1, odr-3, tax -2 , and tax-4) were identified and cloned from $M$. incognita, and their pattern of expression was studied by quantitative reverse transcription polymerase chain reaction (qRT-PCR) in response to different host plant or chemical cues. For Mi-odr-1, in situ hybridization was used to localize expression in the nematode. Functional characterization (via RNAi) of $M i$-odr-1, Mi-odr-3, Mi-tax-2, and $M i$-tax-4 indicated that these genes are crucial for $M$. incognita chemotaxis.

\section{RESULTS}

\section{Annotation and characterization of chemosensory-related genes from $M$. incognita.}

Putative homologs of four Caenorhabditis elegans chemo-

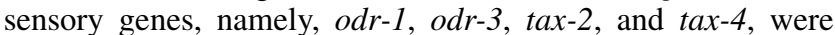
identified in $M$. incognita by BLAST (Supplementary Table $\mathrm{S} 1)$. Based on the best match in the $M$. incognita genome (Blanc-Mathieu et al. 2017), gene-specific primers were designed and were used to PCR-amplify partial coding sequences from J2 complementary (c)DNA. PCR products of these cDNA fragments were cloned into pGEM-T vector and their sequence identity was confirmed via Sanger sequencing. The cDNA fragments of Mi-odr-1 (2,953 bp), Mi-odr-3 (996 bp), Mi-tax-2 (402 bp), and Mi-tax-4 (926 bp) encode open reading frames (ORFs) of 725, 212, 128, and 276 aa, respectively. GenBank accession numbers obtained for these cDNA fragments are MG780832, MG780833, MG780834, and MG780835.

Mi-odr-1 showed high nucleotide sequence similarity with Minc3s00015g01026 (98.25\%) and Minc3s00056g02910 (95.28\%), which belong to different genomic scaffolds (i.e., scaffolds 15 and 56), indicating that $M i$-odr-1 may therefore be present in two copies in M. incognita. Similarly, Mi-odr-3 may also be present in two copies as it showed 99.68 and $97.90 \%$ nucleotide sequence similarity with Minc3s00015g01050 and Minc3s000697g16223, respectively. Mi-tax-2 exhibited 99.50 and $96.86 \%$ sequence similarity to Minc3s00870g18287 and Minc3s00489g13190, respectively. Mi-tax-4 showed 99.79 and $99.75 \%$ homology to Minc3s00870g18287 and Minc3s00870g18288 (these are adjacent genes on the same contig), respectively (Meloidogyne Genomic Resource database). We noted that Mi-tax-2 and Mi-tax-4 showed considerable homology to a same transcript, i.e., Minc3s00870g18287. This similarity is based on partial sequences of Mi-tax-2 and Mi-tax-4, which represent the CNMP_B domain only. This was not surprising as the two channel proteins TAX-2 and TAX-4 share sequence similarity in $C$. elegans. The nucleotide sequence (cloned in the present study) similarity between $\mathrm{Mi}$ tax-2 and Mi-tax-4 was $51.83 \%$.

Genomic DNA from $M$. incognita $\mathrm{J} 2$ was digested either by EcoRI or BamHI and was subjected to Southern hybridization to investigate the copy number of $M i$-odr- 1 and $M i$-odr-3 genes in $M$. incognita. DIG (digoxigenin)-labeled cDNAs of $M i$-odr-1 and $M i$-odr-3 were used as probes on a DNA gel blot containing EcoRI and BamHI-digested DNA of M. incognita. The cDNA of Mi-odr-1 and Mi-odr-3 hybridized specifically to two fragments of nematode DNA in each case. As neither of the target genomic sequences contained EcoRI or BamHI sites, this result suggested that two copies of $M i$-odr-1 and $M i$-odr-3 genes were present in the $M$. incognita genome (Fig. 1A) and is consistent with the above genomic analysis. No hybridization of $M i$-odr-1 and Mi-odr-3 with genomic DNA of tomato (as negative control) was detected (data not shown). DIG-labeled cDNA probes of Mi-tax-2 and Mi-tax-4 failed to show recognizable hybridization signal with EcoRI or BamHI-digested DNA of $M$. incognita in our study.

To examine olfactory gene conservation within phylum Nematoda, sequences of Mi-odr-1, Mi-odr-3, Mi-tax-2, and Mitax-4 were used as search string query to mine the homologous sequences in the nonredundant protein database of NCBI GenBank and WormBase Parasite using the BLASTP algorithm. All four genes had significant hits with the corresponding genes of several nematode species, including free-living, animal-parasitic, and plant-parasitic species (Supplementary Fig. S1). Phylogenetic analyses revealed that odr-1, odr-3, tax2 , and $\operatorname{tax}-4$ genes encoded by PPNs are clustered in separate branches compared with corresponding genes in other nematodes, with cluster nodes supported by more than $70 \%$ bootstrap values in most cases (Supplementary Fig. S2). Interestingly, the $o d r-1$ gene of $M$. incognita was clustered with that of $M$. javanica, $M$. arenaria, and $M$. floridensis, compared with separate branching of $o d r-1$ in cyst nematodes, i.e., H. glycines, Globodera rostochiensis and $G$. pallida, indicating odr-1 sequence divergence between these two groups of PPNs. The high degree of pan-phylum (spanning clades 8, 9, 10, 11, and 12) conservation of $M$. incognita chemosensory genes is apparent from our results showing that odr-1, odr-3, tax-2, and tax-4 are represented in 22, 24, 19, and 23 species in phylum Nematoda, respectively (based on the available sequences in the database).

The ORFs of Mi-odr-1, Mi-odr-3, Mi-tax-2, and Mi-tax-4 were aligned with their selective homologs in M. hapla, M. floridensis, G. rostochiensis, G. pallida, H. glycines, Ditylenchus destructor, Bursaphelenchus xylophilus, and C. elegans. Mi-odr-1 encodes transmembrane, kinase-like, and GCY domains at positions similar to those in the C. elegans gene as well as four conserved cysteine residues in positions consistent with the membrane-bound extracellular domains of GCY gene in C. elegans (Supplementary Fig. S3). Disulfide bonds formed between the conserved cysteine residues may create a conformation required for ligand-binding with receptor proteins (Yan and Davis 2002; Yu et al. 1997). The 212 aa long $M i$-odr-3 ORF is highly similar to the $C$. elegans gene and includes a $\mathrm{G} \alpha$ domain $(85.66 \%$ identical in sequence to the corresponding region in $C$. elegans) at position 16 to 202 . The predicted 128 and 276 aa long Mi-tax-2 and Mi-tax-4 ORFs encode CNMP_B (cyclic nucleotide monophosphate-cGMP/cAMP binding) domain at positions 1 to 80 and 243 to 276 , respectively.

\section{Tissue localization and stage-specific expression of RKN chemosensory genes.}

Based on in-situ hybridization (ISH) experiments, mRNAs of Mi-odr-1 were detected in a cluster of cell bodies associated with amphidial neurons (posterior to the stylet knob) in the anterior region of preparasitic $M$. incognita $\mathrm{J} 2 \mathrm{~s}$ in the dorso-ventral 
plane (Fig. 1B). The proposed neural map of PPN Heterodera schachtii (Wang et al. 2011) was used as a guide to assign the location of $M i$-odr-1 to a specific neuron. As reference, $M$. incognita $\mathrm{J} 2 \mathrm{~s}$ were exposed to $1 \mathrm{mM}$ fluorescein isothiocyanate (FITC) for $16 \mathrm{~h}$ for dye-filling of certain neurons (Fig. 1B). In addition, Mi-odr-1 was expressed in sensory neurons (presumably phasmids [Bellafiore et al. 2008]) in the tail of preparasitic M. incognita J2s. No staining was observed with sense probes as negative control (Fig. 1B). DIG-labeled probes specific to Mi-odr-3, Mi-tax-2, and Mi-tax-4 genes failed to result in a detectable signal in $M$. incognita $\mathrm{J} 2 \mathrm{~s}$ in the present study, possibly because the expression level of these genes was below our detection threshold.

To investigate the expression of Mi-odr-1,Mi-odr-3, Mi-tax2, and Mi-tax-4 in different life stages of RKN, qRT-PCR was performed. Using the expression level in adult females (post egg laying) as reference (value set at 1 and $\log _{10}$-transformed to $0)$, mRNA levels of $M i$-odr-1 were significantly $(P<0.01)$ upregulated in eggs and pre- and postparasitic J2s and were downregulated in $\mathrm{J} 3 / \mathrm{J} 4$ and young females. Conversely, $\mathrm{Mi}$ $o d r-3$ was significantly $(P<0.01)$ upregulated in all other life stages compared with adult females. Mi-tax-2 and Mi-tax-4 showed the highest expression in preparasitic $\mathrm{J} 2 \mathrm{~s}$ and lowest levels in J3/J4 and young females (Fig. 1C). Taken together, qRT-PCR data suggests that the highest level of expression of RKN chemosensory genes occurs in early (egg and mobile) life stages.

\section{RNAi of RKN chemosensory genes and analysis of knockdown phenotypes.}

Double-stranded (ds)RNAs corresponding to Mi-odr-1 (766bp fragment spanning kinase-like and GCY domains), $M i$-odr-3 (524 bp containing the G $\alpha$ domain), Mi-tax-2 (402 bp containing the CNMP_B domain), and Mi-tax-4 (926 bp containing the CNMP_B domain) were synthesized via in vitro transcription. When sequences corresponding to targeted
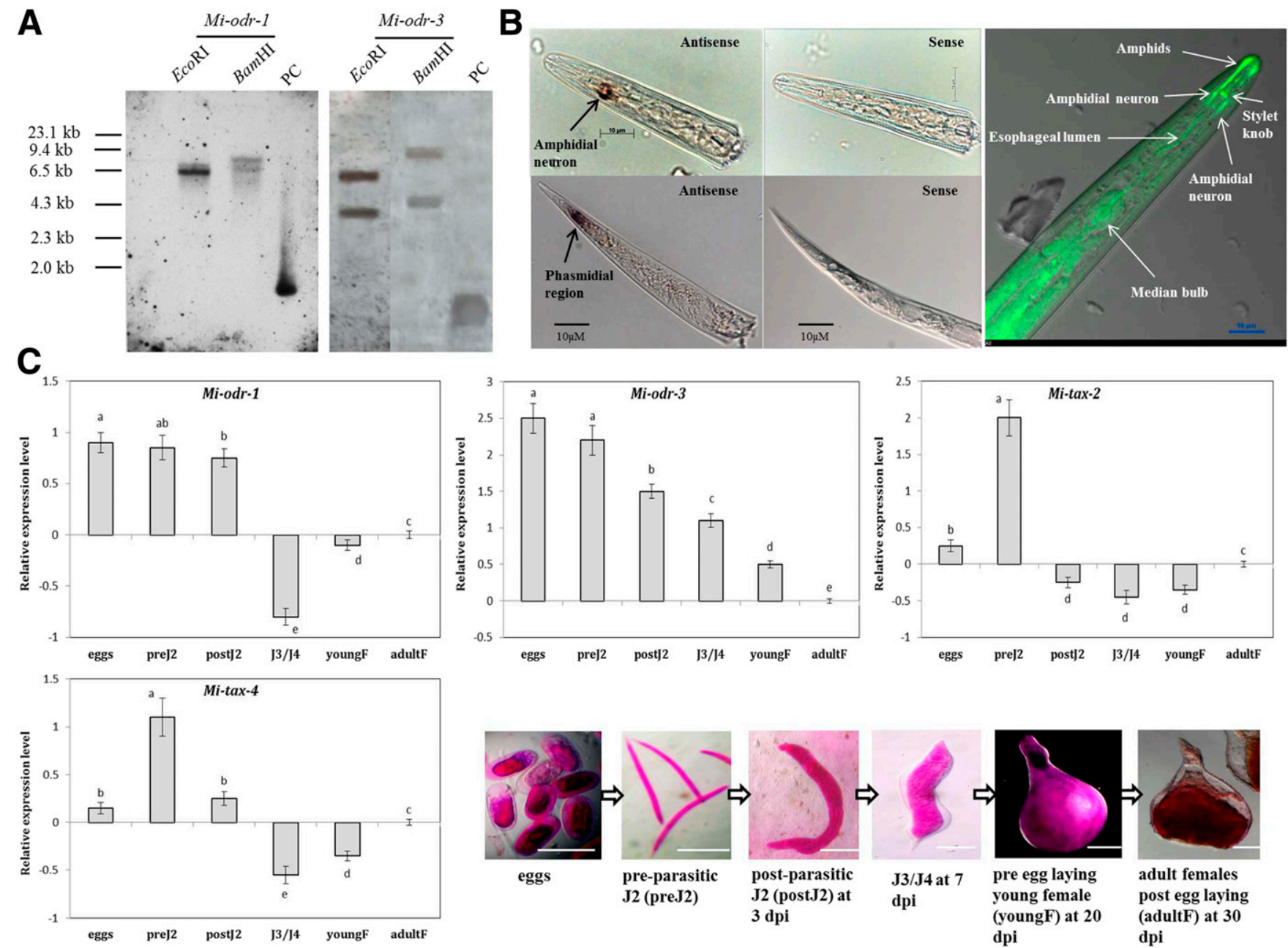

Fig. 1. Molecular characterization of candidate chemosensory genes in Meloidogyne incognita. A, Detection of Mi-odr-1 and Mi-odr-3 genes in M. incognita via Southern hybridization. Blots containing genomic DNA of $M$. incognita digested with EcoRI or BamHI were hybridized with specific cDNA probes of $M i$ $o d r-1$ and Mi-odr-3. Positive control (PC) lanes contained 766- or 524-bp polymerase chain reaction (PCR) products of $M i$-odr-1 or $M i$-odr-3, respectively. B, In-situ hybridization of digoxigenin (DIG)-labeled Mi-odr- 1 cDNA probes in M. incognita J2. Site of Mi-odr-1 expression is signified by dark coloration due to the enzymatic cleavage of a chromogenic substrate (5-bromo-4-chloro-3-indolyl phosphate/nitro blue tetrazolium) by alkaline phosphatase conjugated to antiDIG antibody. Mi-odr-1 expression was located to a cluster of cell bodies in amphidial neurons in anterior and phasmidial regions in the posterior of the nematode body. No staining was observed with sense probes as negative control. The fluorescein isothiocyanate-labeled anterior region of $M$. incognita J2 indicates the position of amphids and amphidial neurons as reference. C, Relative transcript abundance of Mi-odr-1, Mi-odr-3, Mi-tax-2, and Mi-tax-4 genes in different developmental stages of $M$. incognita. Using the transcript level in adult females as reference, candidate genes (expression level was quantified by augmented comparative cycle threshold method) were significantly upregulated, downregulated, or unaltered in different life stages. Each bar represents the $\log _{10}$-transformed mean of quantitative reverse transcription-PCR runs in three biological and three technical replicates with standard errors. Letters indicate significant differences using Tukey's honestly significant difference test $(P<0.01)$. Gene expression was normalized with $M$. incognita $18 S$ rRNA and actin genes. Nematode life stages were stained by acid fuchsin. dpi $=$ days postinoculation. Scale bar $=100 \mu \mathrm{m}$. 
dsRNAs were aligned to each other, no stretches of identical sequences of $>2$ nucleotides between targeted dsRNAs were detected (Supplementary Fig. S4). Additionally, target dsRNA sequences were queried in dsCheck server (Naito et al. 2005). No significant match for processed small interfering (si)RNAs in the existing database of Drosophila melanogaster, Rattus norvegicus, Oryza sativa, and Arabidopsis thaliana was found. However, processed siRNAs of Mi-odr-1, Mi-odr-3, Mi-tax-2, and Mi-tax-4 exhibited homology to GCY-3, Ga, and cyclic nucleotide-gated channel domain of $C$. elegans, respectively.

After soaking the preparasitic J2s in target dsRNAs, qRTPCR was performed to measure the transcript levels of the targeted gene and other olfactory genes. Transcript levels of $M i-o d r-1, M i-o d r-3, M i-t a x-2$, and $M i$-tax-4 exhibited significant downregulation $(P<0.01)$ compared with soaking buffer-treated worms when treated with their corresponding dsRNAs, supporting the idea that target-specific silencing had occurred (Fig. 2A). Additionally, the induced silencing of candidate chemosensory genes likely also downregulated both copies of targeted genes. Transcript levels of Mi-odr-1 were unaltered in $M i$-odr-3 dsRNA-treated worms and vice versa. However, in Mi-tax2- and Mi-tax-4-silenced worms, Mi-odr-3 transcripts were upregulated (Fig. 2A). On the contrary, expression of $M i$-tax-2 and $M i$-tax-4 was significantly attenuated after J2s were treated with $M i-o d r-1$ or $M i-o d r-3$ dsRNAs (Fig. 2A). This suggests that transcriptional repression of $M i$-odr-1 or Mi-odr-3 resulted in the suppression of Mi-tax-2 and Mi-tax-4 transcript levels in RKN J2s. Expression of Mi-odr-1, Mi-odr-3,

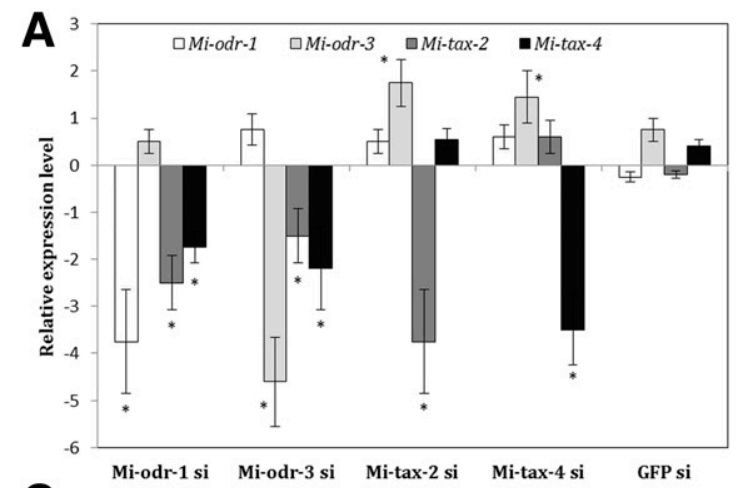

B

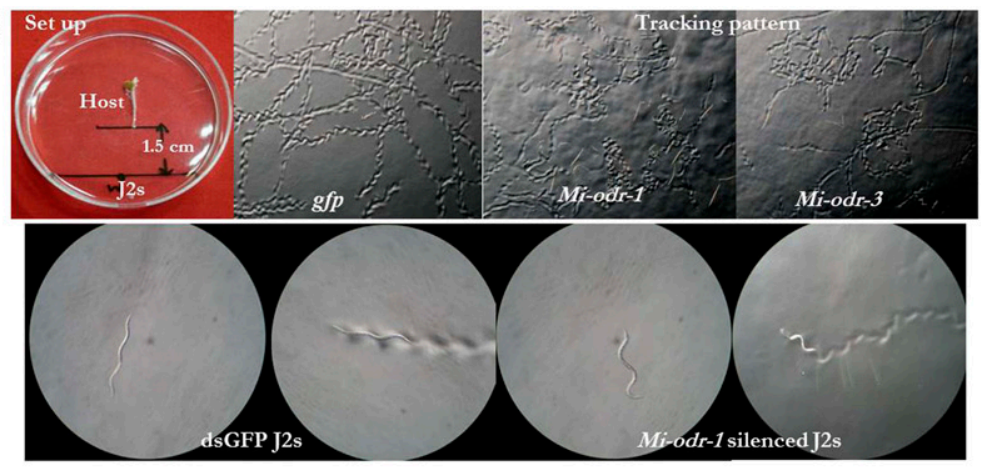

C
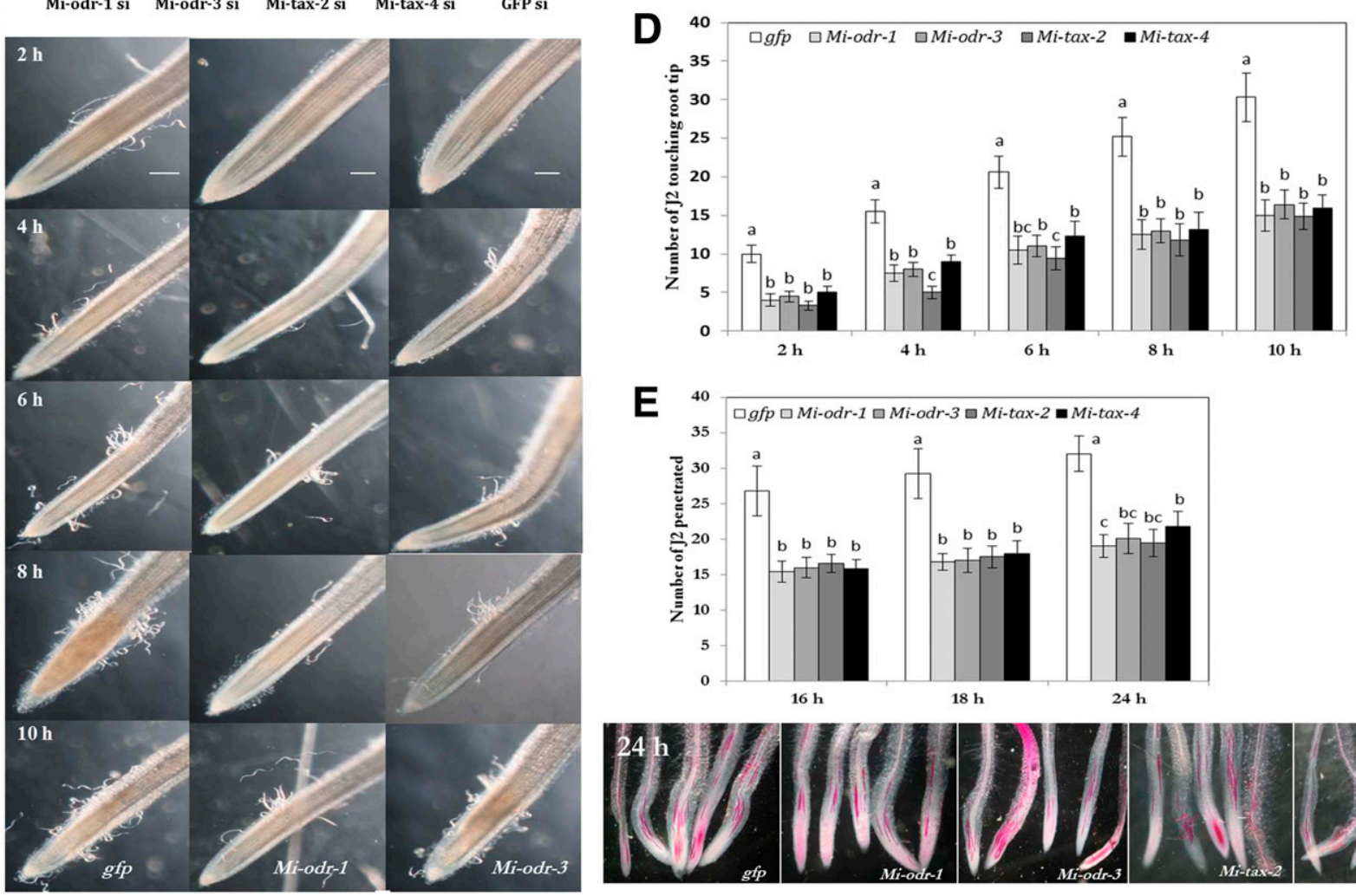

\section{E}
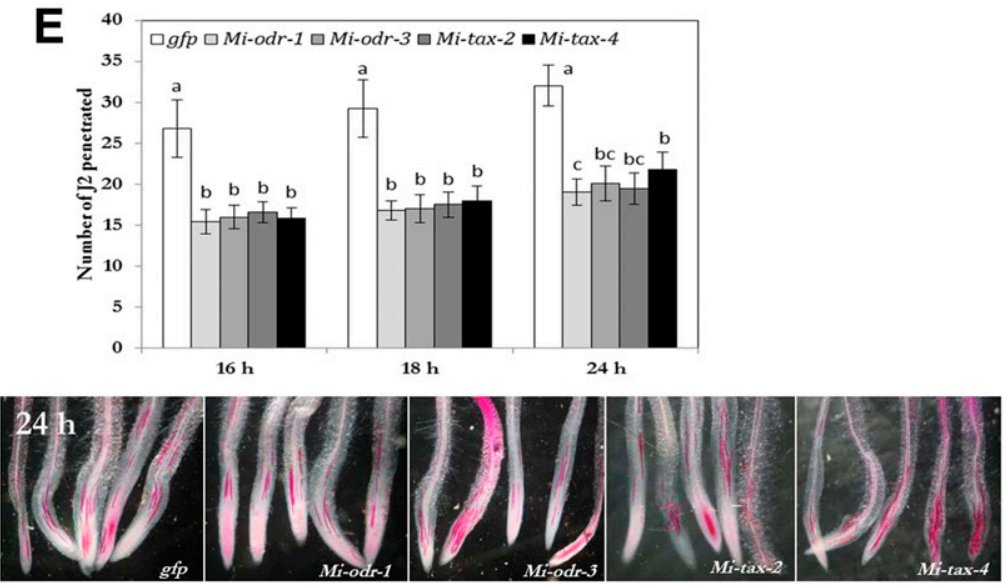

Fig. 2. RNA interference of chemosensory genes perturbs attraction and infection behavior in Meloidogyne incognita. A, Effect of in vitro silencing (si) of Miodr-1, Mi-odr-3, Mi-tax-2, and Mi-tax-4 genes on transcript abundance of corresponding or other olfactory genes in M. incognita preparasitic J2 after $24 \mathrm{~h}$. Gene expression (normalized with M. incognita $18 S$ rRNA and actin genes) was quantified via the augmented comparative cycle threshold method. Each bar represents the $\log _{10}$-transformed mean of quantitative reverse transcription polymerase chain reaction runs in three biological and three technical replicates with standard errors. Asterisks indicate significant differential expression $(P<0.01$, Tukey's honestly significant difference [HSD] test $)$ in comparison with the worms treated with soaking buffer. Nematodes treated with $g f p$ double-stranded (ds)RNA were used as nonnative control. B, Locomotion behavior of dsRNAtreated and control J2s toward tomato root (cv. Pusa Ruby) in PF-127 medium in a Petri dish. J2s were inoculated at a distance of $1.5 \mathrm{~cm}$ from tomato root. Tracks inscribed due to J2 locomotion were documented. C and D, Attraction and E, penetration of Mi-odr-1, Mi-odr-3, Mi-tax-2, and Mi-tax-4 dsRNA-treated J2s toward tomato root tip in PF-127 medium at different timepoints. Scale bar $=500 \mu \mathrm{m}$. Nematodes were stained with acid fuchsin for penetration assay. Each bar (in D and E) represents the mean \pm standard error $(n=12)$, and bars with different letters denote a significant difference at $P<0.05$, Tukey's HSD test. Worms treated with $g f p$ dsRNA were used as the control. 
Mi-tax-2, and Mi-tax-4 was unaltered in green fluorescent protein gene ( $g f p$ ) dsRNA-treated worms (Fig. 2A) suggesting that dsGFP itself did not have any off-target effect on the sensory genes tested.

The resultant worm phenotypes due to RNAi were assessed via several behavioral bioassays. In order to assess the proprioception (locomotion regulation) in dsRNA-treated $\mathrm{J} 2 \mathrm{~s}$, tracking patterns of $\mathrm{J} 2 \mathrm{~s}$ inscribed on Pluronic gel medium PF127 (Wang et al. 2009; Dutta et al. 2011) toward the host root was investigated. Worms treated with dsRNA corresponding to $M i$-odr-1 or $M i$-odr-3 showed different tracking patterns than controls treated with $g f p$ dsRNA. Dwelling behavior predominated in silenced worms, whereas sinusoidal tracks (indicating directed movement) were most predominant in the dsGFP control worms (Fig. 2B). In addition, J2s treated with dsRNAs of Mi-odr-1,Mi-odr-3,Mi-tax-2, and Mi-tax-4 were attracted to tomato root tips in significantly $(P<0.01)$ lower numbers than the dsGFP-treated worms at $2,4,6,8$, and $10 \mathrm{~h}$. The largest differences between numbers of nematodes touching root tips were observed at 8 and $10 \mathrm{~h}$ in control $\mathrm{J} 2 \mathrm{~s}$ compared with silenced worms (Fig. 2C and D). One factor that could affect the accumulation at later timepoints is host penetration, considering that the dsRNA itself may exert toxic effects on nematodes (Dalzell et al. 2009). Therefore, we compared the penetration of the host by the RNAi-treated worms to the $g f p$ dsRNA-treated J2s. Comparatively less penetration of host roots by silenced worms for the chemosensory genes was found at 16, 18, and $24 \mathrm{~h}$ (Fig. 2E), suggesting that the perturbed host recognition due to knockdown of Mi-odr-1, Mi-odr-3, Mi-tax-2, and $M i-\operatorname{tax}-4$ genes may ultimately lead to reduced infection ability of M. incognita $\mathrm{J} 2$.

\section{Host root exudates regulate chemosensory gene expression in $M$. incognita.}

We assessed transcript levels of $M$. incognita chemosensory genes, following the exposure of $\mathrm{J} 2 \mathrm{~s}$ to root exudates of different host plants, by qRT-PCR. J2s treated with tomato (cv. Pusa Ruby), tobacco (cv. Petite Havana), or eggplant (cv. Pusa Purple Long) root exudates for $24 \mathrm{~h}$ showed significantly $(P<$ 0.01 ) higher steady-state mRNA levels of Mi-odr-1, Mi-odr-3, $M i$-tax-2, and Mi-tax-4 genes compared with control worms. By contrast, J2s treated with mustard (cv. Pusa Jai Kisan) or marigold (cv. Arpit) root exudates exhibited lower levels of $\mathrm{Mi}$ $o d r-1, M i$-odr-3, Mi-tax-2, and Mi-tax-4 transcripts. Nematodes treated with maize (cv. Buland) or wheat (cv. Sonalika) root exudates were not significantly different from control worms in transcript levels of chemosensory genes (Fig. 3A). Since tomato, tobacco, and eggplant are good hosts whereas mustard and marigold are poor hosts of RKN (Moens et al. 2009), our data suggest that the perception of specific root exudate components may modulate RKN host-searching behavior by altering the expression of chemosensory genes.

RNAi targeting of Mi-odr-1, Mi-odr-3, Mi-tax-2, and Mi-tax-4 perturbs stylet thrusting and esophageal gland secretion in $M$. incognita.

DsRNA-treated worms were evaluated for head and stylet movement and stylet secretion by adapting the methodology described by Dutta et al. (2012). Compared with control worms, Mi-odr-1, Mi-odr-3, Mi-tax-2, and Mi-tax-4 dsRNA-treated worms showed significantly $(P<0.01)$ fewer stylet thrusts and head movements per minute after incubation in tomato root exudates or resorcinol, a neurotransmitter, for $4 \mathrm{~h}$. Moreover, greatly reduced amounts of salivary secretion around the stylet tip were observed in $M i$-odr-1and $M i$-odr-3 dsRNA-treated J2s compared with control worms (similar results were obtained with Mi-tax-2 and Mi-tax-4 dsRNA-treated worms [data not shown]). However, in distilled water nematode head and stylet movements did not differ significantly among dsRNA-treated and control worms (Fig. 3B). Together these observations suggest that signaling mediated by $M i$-odr-1, Mi-odr-3, Mi-tax-2, and Mi-tax-4 may play a key role in behavioral responses of RKN, either following host perception, in preparation for host invasion, or both.

\section{RNAi targeting of Mi-odr-1, Mi-odr-3, Mi-tax-2, and} Mi-tax-4 inhibits $M$. incognita chemotaxis.

To assess whether knockdown of Mi-odr-1, Mi-odr-3, Mitax-2, and Mi-tax-4 genes causes chemotaxis defects in RKN, an in vitro chemotaxis bioassay to a range of chemicals was carried out in Petri plates containing both agar and PF-127 medium (Shivakumara et al. 2018) (Fig. 3C; described below). First, the response of wild-type $M$. incognita J2s to 20 different volatile compounds (encompassing alcohols, ketones, aromatic compounds, ester, thiazole, and pyrazine at a range of dilutions in water) was measured relative to deionized water. Isoamyl alcohol, 1-butanol, isobutanol, acetone, 2-butanone, diacetyl, ethyl acetate, and thiazole were attractive through a broad range of concentrations. Conversely, 1-octanol and 2-nonanone repelled worms across the concentrations. Benzaldehyde, nitrobenzene, aniline, pyrazine, and 1-nonanol were repulsive at neat and higher concentrations but were attractive at lower concentrations. The opposite was observed with 1-heptanol. Ethanol, isopropanol, chlorobenzene, and toluene did not induce a response in worms (Supplementary Fig. S5). For most compounds, a significant change in behavior was observed when nematodes were exposed to a $1 \%$ concentration of the test compound. Therefore, in subsequent studies, this concentration was used for assessing response to volatile compounds.

In $C$. elegans, adaptation or reduced response to chemicals after prolonged exposure to a chemical has been widely observed (Bargmann et al. 1993). The adaptation of wild-type $M$. incognita $\mathrm{J} 2$ with isoamyl alcohol, 2-butanone, and nitrobenzene displayed interesting phenotypes. We recorded the loss of naive response of adapted nematodes because $1 \mathrm{~h}$ of preexposure to the tested volatile led to nonsignificant chemotactic response of $\mathrm{J} 2 \mathrm{~s}$ in the assay plate while exposed to the same chemical (Supplementary Fig. S6). Since $24 \mathrm{~h}$ of recovery failed to restore the attraction to tested volatiles by unexposed or naive $\mathrm{J} 2 \mathrm{~s}$, it can be speculated that pre-exposure to volatiles may saturate RKN chemoreceptors, which affects further processing of the olfactory signal. In addition, wild-type RKN J2s also showed selective discrimination response while exposed to two different volatiles at a time on the assay plate.

In contrast to nematodes exposed to water or $g f p$ dsRNAtreated J2s, Mi-odr-1, Mi-odr-3, Mi-tax-2, and Mi-tax-4 dsRNA-treated worms did not show any significant $(P<$ 0.01) attraction response toward isoamyl alcohol, 1-butanol, acetone, 2-butanone, diacetyl, nitrobenzene, aniline, ethyl acetate pyrazine, and thiazole. Similarly, when exposed to selective repellents (1-heptanol, 1-octanol, 1nonanol, and 2-nonanone), in contrast to control worms, $M i-o d r-1, M i-o d r-3, M i$-tax-2, and Mi-tax-4 dsRNAtreated worms did not show any significant repulsion response (Fig. 3C). These findings indicate that silencing $\mathrm{Mi}$ $o d r-1, M i$-odr-3, Mi-tax-2, or Mi-tax-4 results in defective chemotaxis of RKN toward volatile compounds.

While control worms showed attraction toward root exudates of tomato, tobacco, and eggplant (good hosts of RKN) and were repelled by exudates of mustard and marigold (poor hosts of RKN), Mi-odr-1, Mi-odr-3, Mi-tax-2, and Mi-tax-4 dsRNA-treated J2s did not show any significant $(P<0.01)$ attraction or repulsion response to any of these root exudates. Chemotaxis behavior did not differ significantly in control or silenced worms while exposed to maize or wheat exudates (Fig. 4A). 
In order to assess the effect of silencing chemosensory genes on $M$. incognita chemotaxis to nonvolatile compounds of plant origin, we first evaluated the attraction/repulsion response of wild-type $\mathrm{J} 2 \mathrm{~s}$ to a range of concentrations (50 to $250 \mu \mathrm{M})$ of nonvolatiles, including organic acids, amino acids, phytohormones, and carbohydrates (Supplementary Fig. S7). Ascorbic, citric, and lactic acids were attractive at concentrations of 200 and $250 \mu \mathrm{M}$, whereas oxalic acid repelled worms at a concentration of $200 \mu \mathrm{M}$. Phenolic compounds were repellent at concentrations of 200 and $250 \mu \mathrm{M}$. Indole-3-acetic acid (IAA), indole-3-butyric acid (IBA), gibberellin, salicylic acid (SA), and methyl jasmonate (MeJA) were attractive at concentrations of 150 to $250 \mu \mathrm{M}$. The amino acids arginine and alanine were attractive at concentrations of 4 and $5 \mathrm{mM}$, while glutamic and aspartic acids were repellent at a concentration of $5 \mathrm{mM}$. Almost all the carbohydrates were attractive at higher concentrations, i.e., 4 and $5 \mathrm{mM}$, except mannitol and lactose, which were attractive at $1 \mathrm{mM}$. The remaining compounds did not lead to detectable attraction or repulsion at any of the concentrations tested.

In contrast to $g f p$ dsRNA-treated J2s, Mi-odr-1, Mi-odr-3, $M i$-tax-2, and Mi-tax-4 dsRNA-treated worms did not, for the most part, show any significant $(P<0.01)$ attraction response toward attractants including ascorbic, citric, and lactic acids, IAA, IBA, gibberellin, SA, MeJA, arginine, alanine, mannitol, arabinose, glucose, sucrose, fructose, galactose, lactose, xylose, and sorbitol. Similarly, when exposed to repellents (oxalic acid, quercetin, coumaric acid, glutamic acid, aspartic acid), unlike dsGFP worms, Mi-odr-1, Mi-odr-3, Mi-tax-2, and Mi-tax-4 dsRNA-treated worms did not show any significant repulsion response (Fig. 4B). Taken together, our data suggest that disruption of Mi-odr-1, Mi-odr-3, Mi-tax-2, or Mi-tax-4 causes severe chemotaxis defects in RKN to nonvolatile compounds of plant origin, including carbohydrates, phytohormones, amino acids, organic acids and phenolic compounds.

\section{RNAi targeting of Mi-odr-1, Mi-odr-3, Mi-tax-2, and Mi-tax-4 disrupts ascaroside-mediated signaling in $M$. incognita.}

Ascarosides (dideoxy sugar ascarylose linked to fatty acidlike side chains) are nematode pheromones that regulate diverse behaviors including aggregation, sex-specific attraction/ repulsion, and olfactory plasticity in C. elegans. Ascarosides target chemoreceptors of amphid neurons, specifically Gprotein coupled receptors (Choe et al. 2012). The ascaroside molecule ascr\#18 was the most abundant species detected in the
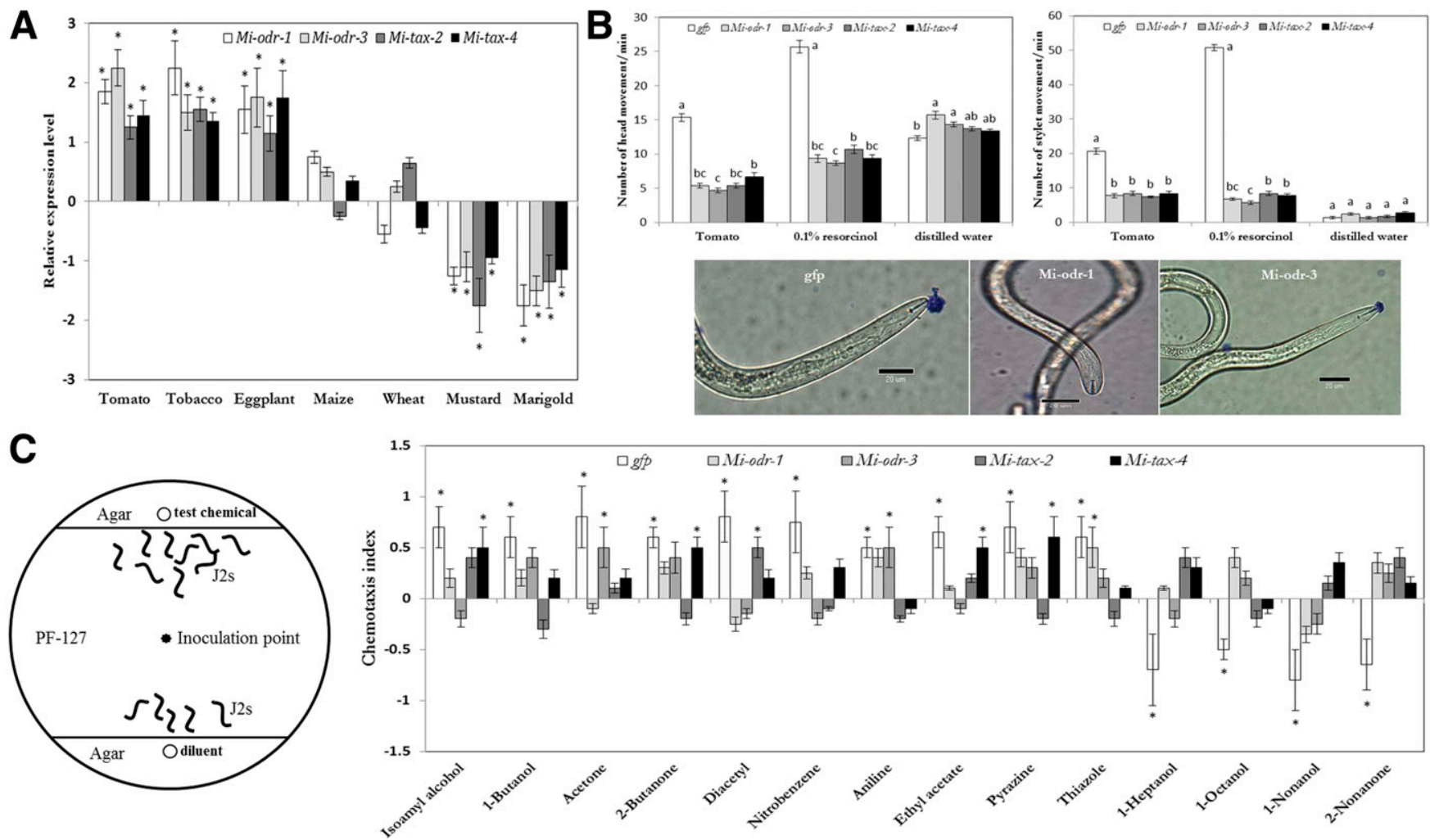

Fig. 3. RNA interference of chemosensory genes affects Meloidogyne incognita exploratory behavior to host root exudates as well as chemotaxis to volatile compounds. A, Expression pattern of $M i$-odr-1, Mi-odr-3, Mi-tax-2, and Mi-tax-4 transcripts in $M$. incognita preparasitic J2s post exposure to root exudates of tomato, tobacco, eggplant, maize, wheat, mustard, and marigold. Gene expression (normalized with M. incognita 18S rRNA and actin genes) was quantified via the augmented comparative cycle threshold method. Each bar represents the $\log _{10}$-transformed mean of quantitative reverse transcription polymerase chain reaction runs in three biological and three technical replicates with standard errors. Asterisks indicate significant differential expression $(P<0.01$, Tukey's honestly significant difference [HSD] test) in comparison with the freshly hatched worms. B, Head movement and stylet movement of $M i$-odr- $1, M i$-odr-3, $M i$ $\operatorname{tax}$-2, and Mi-tax-4 double-stranded (ds)RNA-treated $\mathrm{J} 2 \mathrm{~s}$ induced tomato root exudates and neurotransmitter resorcinol at $4 \mathrm{~h}$. Each bar represents the mean \pm standard error $(n=6)$, and bars with different letters denote a significant difference at $P<0.01$, Tukey's HSD test. Nematodes treated with $g f p$ dsRNA were used as control. Photomicrographs show the negligible amount of secreted proteins (due to reaction with Commassie Brilliant Blue R250) around the stylet tip in $\mathrm{Mi}$ $o d r-1$ and $M i$-odr-3 dsRNA-treated $\mathrm{J} 2 \mathrm{~s}$ compared with the greater amount of secreted proteins in control $\mathrm{J} 2$, while incubated with $0.1 \%$ resorcinol for $4 \mathrm{~h}$. C, Schematic of an in vitro chemotaxis assay plate. Nematode inoculation point is $1.5 \mathrm{~cm}$ equidistant from the agar-PF-127 junction; diluents (in which test chemicals were dissolved) were applied in another well as control. Chemotactic response of $M i$-odr-1, $M i$-odr-3, $M i$-tax-2, and $M i$-tax-4 dsRNA-fed $M$. incognita $\mathrm{J} 2 \mathrm{~s}$ to selective volatile compounds compared with gfp dsRNA-fed J2s. Values show attraction (positive index) or repulsion (negative index). Asterisks indicate significantly different $(P<0.01$, Tukey's HSD test) chemotactic response of $\mathrm{J} 2$ to test compounds while compared with water as negative control. Five microliters of test compounds $\left(10^{-2}\right.$ concentration) were screened against approximately $100 \mathrm{~J} 2 \mathrm{~s}$. Error bars represent standard error of three biological and three technical replicates. 
exometabolome of RKN J2 and has also been detected in other PPNs, including Pratylenchus brachyurus (Manosalva et al. 2015). In C. elegans, odr-1 mutants showed reduced sensitivity to ascarosides, indicating a role of $o d r-1$ in ascaroside perception (Ludewig and Schroeder 2013). Since ascaroside signaling is conserved throughout the phylum Nematoda, we evaluated the response of Mi-odr-1, Mi-odr-3, Mi-tax-2, and Mi-tax-4 dsRNAtreated J2s to synthetic ascarosides ascr\#9, which was not detected in the exometabolome of RKN, and ascr\#18 in PF-127 medium in a Petri plate. In contrast to ascr\#9, ascr\#18 elicited a significant $(P<0.01)$ attractive response in wild-type $\mathrm{J} 2 \mathrm{~s}$ to 0.5 , 1,5 , and $25 \mathrm{fmol}$, relative to water as negative control (Fig. 5A). However, upon exposure to $5 \mathrm{fmol}$ ascr\#18, J2s treated to silence chemosensory genes did not show any significant attractive response, whereas $g f p$ dsRNA-treated worms responded the same as wild type (Fig. 5B). This suggests that knockdown of RKN chemosensory genes results in perturbed nematode response toward ascaroside molecules.

\section{DISCUSSION}

The current study presents the molecular and functional characterization of hitherto unexplored chemosensory genes in the most economically important PPN, $M$. incognita. First, four putative genes (Mi-odr-1, Mi-odr-3, Mi-tax-2, and Mi-tax-4) were identified, via in silico mining based on characterized $C$. elegans genes, and were cloned from the cDNA of $M$. incognita. Comparative bioinformatics analyses revealed that these four chemosensory genes in $M$. incognita are phylogenetically more distant than their homologs in animalparasitic or free-living worms (a probable odr- 1 sequence divergence was observed among cysts and RKNs). This finding is not surprising, considering that PPNs have evolved independently on at least four separate occasions (Kikuchi et al. 2017). In addition, the putative evolution of the function of these chemosensory gene homologs may be related to the differential host range of cysts and RKNs. Identification of RKNspecific chemosensory genes would provide a valuable repository of targets for drug or nematicide candidates that may elicit broad-spectrum activities against RKNs but not off-target worms.

Our Southern hybridization analysis suggests the presence of two copies each of Mi-odr-1 and Mi-odr-3 in the M. incognita genome. Genomic analysis also supports the presence of two highly homologous copies of the chemosensory genes. This was not unexpected, as $M$. incognita is an asexual hybrid and
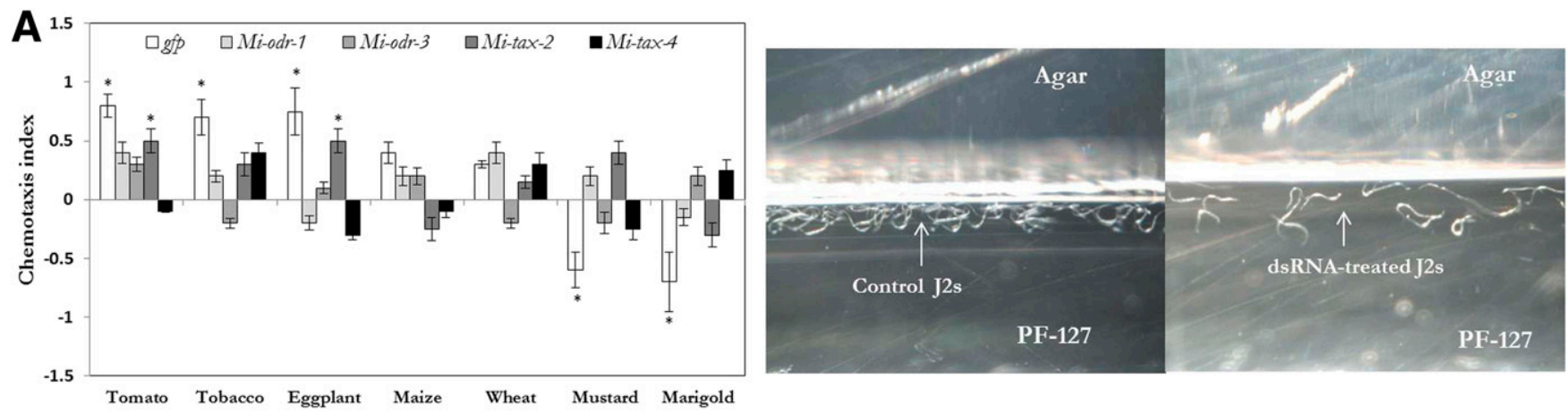

B

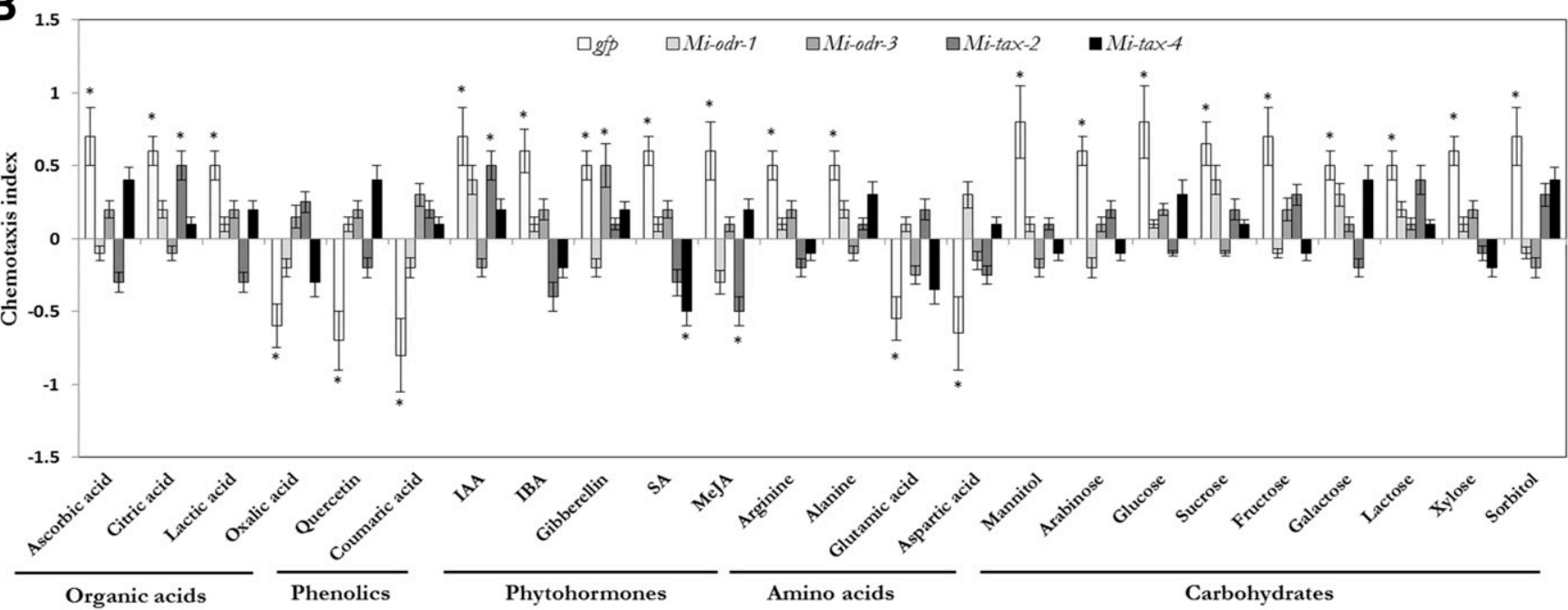

Fig. 4. RNA interference of chemosensory genes causes chemotaxis defects in Meloidogyne incognita toward host root exudates and nonvolatile compounds. A, Chemotactic response of Mi-odr-1, Mi-odr-3, Mi-tax-2, and Mi-tax-4 double-stranded (ds)RNA-fed M. incognita J2s to root exudates of tomato, tobacco, eggplant, maize, wheat, mustard, and marigold compared with $g f p$ dsRNA-fed J2s. Values show attraction (positive index) or repulsion (negative index). Asterisks indicate significantly different $(P<0.01$, Tukey's honestly significant difference [HSD] test) chemotactic response of $\mathbf{J} 2$ to root exudates while compared with water as negative control. Ten microliters of exudates were screened against approximately $100 \mathrm{~J} 2 \mathrm{~s}$. Error bars represent standard error of three biological and three technical replicates. A close-up view of the assay plate shows that, compared with dsRNA-treated J2s, a greater number of control J2s were accumulated near the attractant source (agar-PF-127 junction) while exposed to root exudates of tomato. B, Chemotactic response of Mi-odr-1, Mi-odr-3, Mitax-2, and Mi-tax-4 dsRNA-fed M. incognita J2s to selective nonvolatile compounds compared with gfp dsRNA-fed J2s. Values show attraction (positive index) or repulsion (negative index). Asterisks indicate significantly different $(P<0.01$, Tukey's HSD test) chemotactic response of J2 to test compounds while compared with water as negative control. Ten microliters of test compounds (organic acids, phenolic compounds, and phytohormones at $200 \mu \mathrm{M}$ concentration, amino acids and carbohydrates at $5 \mathrm{mM}$, except mannitol and lactose at $1 \mathrm{mM}$ concentration) were screened against approximately $100 \mathrm{~J} 2 \mathrm{~s}$. Error bars represent standard error of three biological and three technical replicates. 
many of its genes are present in two diverged copies (Abad et al. 2008; Szitenberg et al. 2017). According to ISH analysis, mRNAs of Mi-odr-1 appear to be localized to a cluster of cell bodies associated with amphidial neurons and phasmids. Our result is similar to a study by Yan and Davis (2002), in which HG- $g c y-2$ transcripts were found to be localized to amphid and tail neurons of preparasitic $H$. glycines $\mathrm{J} 2$. In C. elegans, odr-1 GCY functions in odorant discrimination and is involved in downstream signaling of olfactory receptors. The localization of expression of odr- 1 to specific sensory neurons (i.e., AWC and AWB) in C. elegans also indicated that $o d r-1$ is directly involved in chemoreception (L'Etoile and Bargmann 2000). Considering that neural connectivity is conserved within phylum Nematoda, the localization of $M i$-odr-1 transcripts that we observed by ISH is consistent with a key role in chemoreception in $M$. incognita $\mathrm{J} 2 \mathrm{~s}$.

qRT-PCR data revealed that Mi-odr-1, Mi-tax-2, and Mi-tax4 transcript levels were highest in the eggs and mobile, early parasitic stages, i.e., pre- and postparasitic J2 stages. This timing is consistent with a role of these genes in nematode host seeking and locating a suitable feeding site inside the host. However, Mi-odr-3 was expressed in all the life stages of RKN. Thus, Mi-odr-3 may have some regulatory role other than chemosensation in RKN. It is to be noted that $o d r-3$ exhibited the ability to regulate morphogenesis of the olfactory cilia in C. elegans (Roayaie et al. 1998).

By silencing nematodes using in-vitro RNAi soaking protocols, we demonstrated that expression of the four putative RKN chemosensory genes were readily downregulated. Transcript quantitation indicated that this downregulation was targetspecific. Transcript levels of $M i$-odr- 1 were unaltered in $M i$ $o d r$-3-silenced worms and vice versa. Intriguingly, Mi-odr-3 transcripts were upregulated in Mi-tax2- or Mi-tax-4-silenced worms, possibly because nematodes have compensated for the downregulation of target transcripts in favor of the $G$ protein signaling during chemotaxis. Several other examples of expression interactions among PPN genes have been reported (Bakhetia et al. 2008; Shivakumara et al. 2016, 2017). Conversely, $M i$-tax-2 and $M i$-tax-4 transcripts were downregulated in $M i$-odr-1- or Mi-odr-3-silenced worms. Notably, tax-2 and tax-4 nucleotide-gated channels are transduced downstream of the $\mathrm{G}$ protein signaling in neurons of $C$. elegans; GCYs are the main cGMP source for TAX-2/TAX-4 function (Coburn and Bargmann 1996; Komatsu et al. 1996; L'Etoile and Bargmann 2000). As RNAi-induced transcriptional repression of $M i$-odr-1

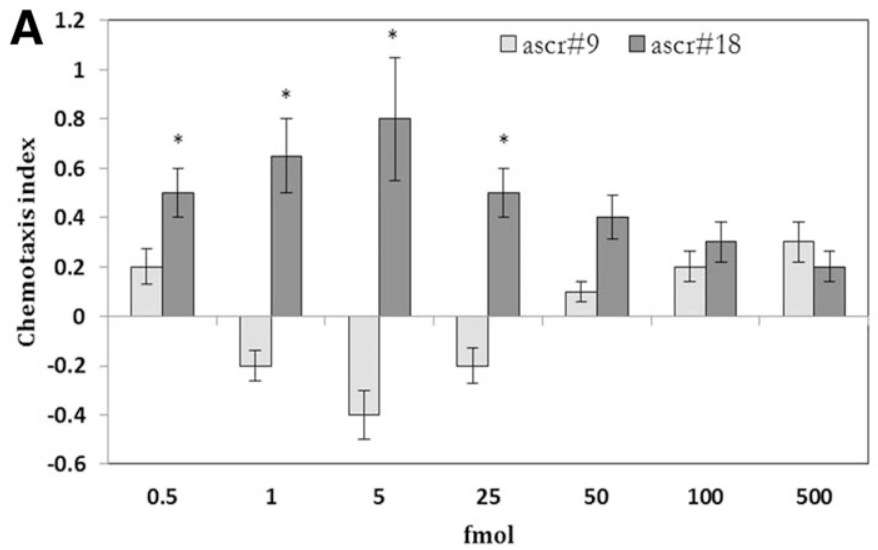

or Mi-odr-3 caused suppression of Mi-tax-2 or Mi-tax-4 transcripts in RKN J2s in the current study, it can be speculated that $M i$-tax-2 and Mi-tax-4 function downstream of Mi-odr-1 and Mi-odr-3 in the chemotaxis pathway of M. incognita as it does in C. elegans (Supplementary Fig. S8).

Loss of Mi-odr-1, Mi-odr-3, Mi-tax-2, and Mi-tax-4 activity via RNAi also resulted in pronounced abnormalities in worm behavior in the presence of host root tips, as compared with control worms. Based on their tracking pattern on the surface of the PF-127 medium, worms silenced for candidate chemosensory genes exhibited aberrant locomotory behavior toward tomato roots compared with control worms. Consequently, olfactory gene-silenced worms were attracted to tomato root in comparatively lesser number than control worms at different timepoints up to $10 \mathrm{~h}$ postinoculation. From $12 \mathrm{~h}$ onwards, no contrasting phenotypes of silenced and control worms were documented, which could be attributed to the transient effect of RNAi (Rosso et al. 2009) or a majority of the attracted nematodes had already invaded the host root. The results of a penetration study at 16,18 , and $24 \mathrm{~h}$ corroborated the outcome of the attraction experiment, suggesting that RNAi-mediated knockdown of olfactory genes in RKN negatively alters both host location and infection behaviors.

Discrete bioactive compounds present in plant root exudates have been hypothesized to regulate PPN chemotaxis toward selective hosts (Curtis 2008; Dutta et al. 2012; Hooks et al. 2010). This prompted us to investigate whether root exudates of different hosts regulate transcription of RKN genes that have a role in RKN chemotaxis. In our study, transcripts of Mi-odr-1, Mi-odr-3, Mi-tax-2, and Mi-tax-4 were upregulated when RKN J2s were exposed to exudates of tomato, tobacco, and eggplant. By contrast, olfactory gene transcripts were either downregulated or unaltered while $\mathrm{J} 2 \mathrm{~s}$ were exposed to mustard and marigold or maize and wheat exudates. Earlier, Arabidopsis thaliana root exudates were shown to regulate $M$. incognita gene expression prior to penetration, suggesting that PPNs can perceive root signals and respond by modulating their gene expression and behavior (Teillet et al. 2013).

While being attracted to growing root tips, RKN J2s display a characteristic exploratory behavior including increased motility, stylet thrusting, and release of stylet secretions that may aid in root penetration (Dutta et al. 2012; von Mende 1997; Zhao et al. 2000). Similar observations were recorded for cyst nematodes as well (Grundler et al. 1991; Smant et al. 1997). In the present study, substantially reduced head and stylet

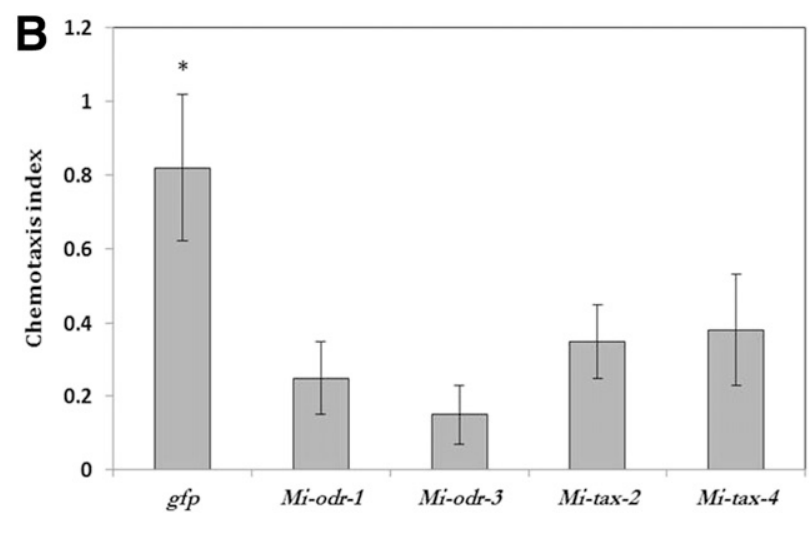

Fig. 5. RNA interference of chemosensory genes alters ascaroside-mediated behavioral modulation in Meloidogyne incognita. A, Behavioral response of wildtype $M$. incognita $\mathbf{J} 2$ to ascr\#9 and ascr\#18 at 0.5 to $500 \mathrm{fmol}$, and B, Mi-odr-1, Mi-odr-3, Mi-tax-2, and Mi-tax-4 dsRNA-fed M. incognita $\mathbf{J} 2$ s (compared with gfp double-stranded [ds]RNA-fed worms) to ascr\#18 at $5 \mathrm{fmol}$. Ethanol was used as diluent for ascarosides (ethanol stock was diluted in water). Chemotaxis bioassays show attraction (positive index) or repulsion (negative index) values. Asterisks indicate significantly different $(P<0.01$, Tukey's honestly significant difference test) chemotactic response of $\mathrm{J} 2$ to ascarosides while compared with water as negative control. Ascarosides were pipetted at a distance of $1 \mathrm{~cm}$ from the center of the assay plate; $100 \mathrm{~J} 2 \mathrm{~s}$ were inoculated at the center. Error bars represent standard error of three biological and three technical replicates. 
movement and esophageal gland secretion were observed in worms silenced for candidate chemosensory genes $M i$-odr-1, Mi-odr-3, Mi-tax-2, and Mi-tax-4 suggesting that their expression is important for initial exploratory behavior in RKN host recognition and infection.

Using an adaptation assay, we have provided evidence for long-term habituation in wild-type $M$. incognita worms to volatile compounds such as isoamyl alcohol, 2-butanone, and nitrobenzene. Additionally, wild-type $M$. incognita worms can also selectively discriminate these compounds. This behavior parallels the aversive olfactory learning in C. elegans toward pathogens (Zhang et al. 2005). Olfactory gene-silenced RKN J2s did not show attraction to isoamyl alcohol, 1-butanol, acetone, 2-butanone, diacetyl, nitrobenzene, aniline, ethyl acetate pyrazine, and thiazole which was found to be attractant to control J2s. Accordingly, unlike control J2s, silenced J2s did not show repulsion to 1-heptanol, 1-octanol, 1-nonanol, and 2nonanone. This suggests that Mi-odr-1,Mi-odr-3,Mi-tax-2, and $M i$-tax-4 play a critical role in determining $M$. incognita attraction or repulsion toward volatile compounds. In C. elegans, AWA, AWB, and AWC neurons that house odr genes aid in odor discrimination and nociception to volatile compounds (Bargmann et al. 1993; L'Etoile and Bargmann 2000; Roayaie et al. 1998).

RNAi of Mi-odr-1,Mi-odr-3,Mi-tax-2, and Mi-tax-4 resulted in the defective chemotaxis in RKN toward various host root exudates. Low molecular-weight carbohydrates, amino acids, and organic acids present in the host root exudates influence bacterial chemotaxis to host roots (Bacilio-Jiménez et al. 2003; Kravchenko et al. 2003). Likewise, the adaptive chemosensory response of $M$. incognita and $G$. pallida toward various phytochemicals, including hormones, organic acids, amino acids, and carbohydrates, has been demonstrated (Fleming et al. 2017). Phytohormones, particularly IAA, which has been reported to bind to RKN chemosensory organs, have been implicated in the host recognition process of PPNs (Curtis 2008), whereas phenolic compounds elicited strong repellent response in PPNs (Fleming et al. 2017; Wuyts et al. 2006). PPN chemotactic affinity to ethylene and SA has also been described in several reports (Wubben et al. 2001; Wuyts et al. 2007). The nematode (including PPNs) cuticle surface may harbor carbohydrate moieties that recognize reducing sugars, such as glucose, mannose, galactose, and others, that diffuse to the nematode sensory receptor by competitive displacement of coupled molecules (Zuckerman and Jansson 1984). The presence of glycan-binding carbohydrate moieties has been demonstrated in the animal-parasitic worm Haemonchus contortus (Lu et al. 2017). In the present study, we demonstrated that RNAi of Mi-odr-1, Mi-odr-3, Mi-tax-2, and Mi-tax-4 profoundly affected the chemotaxis of RKN J2 to nonvolatile compounds of plant origin, including carbohydrates, phytohormones, amino acids, organic acids, and phenolic compounds. Additionally, response to the nematode pheromone ascaroside \#18 was impeded in RKN with RNAi- silenced chemosensory gene candidates.

Together, our results indicate that the expression of the four chemosensory gene candidates of $M$. incognita, namely, $M i$ $o d r-1, M i$-odr-3, Mi-tax-2, and Mi-tax-4, are crucial for the $M$. incognita host finding and chemotaxis to various volatile and nonvolatile compounds. We have provided the evidence for long-term habituation in wild-type worms to specific chemicals. Using qRT-PCR analysis, we speculate that Mi-tax-2 and Mi-tax-4 may function downstream of Mi-odr-1 and Mi-odr-3 in the chemotaxis pathway of $M$. incognita. In our ISH assay, expression of Mi-odr-1 was localized to the M. incognita sensory organs, i.e., amphidial neuron and phasmids. Intriguingly, upon exposure to root exudates of various host plants, the expression of RKN chemosensory genes was selectively altered. It can be speculated that $M$. incognita perceives chemical gradients, via one or more core chemosensory genes such as Mi-odr-1 and Mi-odr-3 followed by Mi-tax-2 and Mi-tax-4mediated signaling in the sensory organs, and selectively chemo-orients to specific cues.

This newly reported behavioral response in a PPN due to the function of specific olfactory genes will aid in understanding the early stage of plant-nematode interactions. In order to develop novel management strategies, the vulnerable points in that interaction can be targeted to disrupt the nematode hostfinding process.

\section{MATERIALS AND METHODS}

\section{Bioinformatics.}

Protein sequences of $C$. elegans chemosensory genes odr-1 (L'Etoile and Bargmann 2000), odr-3 (Lans et al. 2004), tax-2, and tax-4 (Coburn et al. 1998) were used as search strings against the Meloidogyne Genomic Resource database for translated nucleotide sequences in $M$. incognita. Those sequences were interrogated against $C$. elegans genome in the Wormbase Parasite database. The top scoring reciprocal BLAST hits (sequences with smallest expect value and largest bit score) were designated as the $M$. incognita candidate genes. Return sequences were translated into all six reading frames (ExPASy SIB Bioinformatics Resource portal) and were examined for conserved domains (GCY for ODR-1, G $\alpha$ protein for ODR-3, cAMP/cGMP binding motif for TAX-2 and TAX4), using InterProScan, SMART, and the Motif database algorithm. Gene-specific primers were designed (Integrated Data Technologies) against the putatively assigned different $M$. incognita chemosensory genes. Primer details are documented in Supplementary Table S2.

\section{Nematodes.}

A pure culture of $M$. incognita race 1 was maintained on eggplant (Solanum melongena cv. Pusa Purple Long) in a greenhouse. Egg masses were collected from the galled roots of a two-month-old infected plant, using sterilized forceps, and were kept for hatching in a modified Baermann assembly (Whitehead and Hemming 1965). Freshly hatched J2s were used for subsequent experiments. For stage-specific expression analysis of chemosensory genes, different life stages of RKN were carefully dissected out of the infected root, using sterilized forceps under the microscope.

\section{Molecular characterization of RKN chemosensory genes.}

Total RNA was isolated from preparasitic J2s of $M$. incognita and was reverse-transcribed to cDNA, using random primers (SuperScript VILO, Invitrogen), as described previously (Shivakumara et al. 2016). The target sequences of each of the candidate genes, i.e., Mi-odr-1, Mi-odr-3, Mi-tax-2, and Mi-tax4, were PCR-amplified from the cDNA using Platinum Taq DNA polymerase (Thermo Fisher Scientific), following the manufacturer instructions. Amplified fragments were cloned into pGEM$\mathrm{T}$ vector (Promega) and the identity of the insert was confirmed via Sanger sequencing. Predicted proteins of the candidate genes with conserved motifs were aligned with their homologs in other nematode species, using BoxShade (Expasy Bioinformatics Resource portal) and MultAlin multiple sequence alignment tools, using default settings. A phylogenetic tree was constructed using the MEGA6 bioinformatics tool, following the maximum likelihood method based on the Le and Gascuel model, with selection of the appropriate model using MODELTEST (Posada and Crandall 1998). The bootstrap consensus tree was inferred from 1,000 replicates, to represent the evolutionary history, and 
branches corresponding to partitions reproduced in less than $50 \%$ bootstrap replicates were collapsed. Sequence alignments were manually corrected by eliminating the gaps and missing data. For ODR-1 and ODR-3, the tree was rooted using Drosophila melanogaster as the outgroup. For TAX-2 and TAX-4, the tree was rooted differently, as no tax- 2 and tax -4 ortholog was found in D. melanogaster.

The differential expression of candidate transcripts at six developmental stages (eggs, preparasitic J2, postparasitic J2, $\mathrm{J} 3 / \mathrm{J} 4$, young, and adult females) of RKN was analyzed by qRTPCR. RNA was isolated from different life stages and was converted to cDNA, as described above. the qRT-PCR reaction was performed with three biological and three technical replicates of each nematode sample in a Realplex ${ }^{2}$ thermal cycler (Eppendorf) by following the protocol described earlier (Shivakumara et al. 2017). Gene expression was normalized using $18 S$ rRNA (GenBank: HE667742) as reference. Fold change in expression was quantified via an augmented comparative cycle threshold method (Livak and Schmittgen 2001) and was $\log _{10}$-transformed.

For Southern hybridization, genomic DNA $(6 \mu \mathrm{g})$ was extracted from $M$. incognita J2 using Purelink genomic DNA mini kit (Invitrogen), following the manufacturer instructions, and was digested with either EcoRI or BamHI (New England Biolabs). Probe synthesis, hybridization, and blot development was carried out as described previously (Kumari et al. 2017).

Mi-odr-1 ISH probe template (207 bp; Supplementary Fig. S9) was generated by PCR from cDNA cloned in pGEM-T. PCR products were visualized on $1.2 \%(\mathrm{wt} / \mathrm{vol})$ agarose gel and were sequence verified as described above. DIG-labeled singlestranded sense and antisense DNA probes were generated from cDNA template by asymmetric PCR in the following reaction: $5 \mu \mathrm{l}$ of $10 \times$ PCR buffer, $3 \mu \mathrm{l}$ of $\mathrm{MgCl}_{2}, 2 \mu$ of DIG dNTP mix (Roche), $1 \mu \mathrm{l}$ of sense or antisense primer $(20 \mu \mathrm{M}), 2 \mu \mathrm{l}$ of probe template, $0.25 \mu$ l of Platinum Taq DNA polymerase, and double-distilled $\mathrm{H}_{2} \mathrm{O}$ to $50 \mu$ l. Hybridized probes were detected with substrates 5-bromo-4-chloro-3-indolyl phosphate/nitro blue tetrazolium. Nematode fixation, permeabilization, probe hybridization, and detection were performed as described by Kimber et al. (2002). Specimens mounted on glass slides were examined in Zeiss Imager M2m compound microscope.

\section{Functional characterization \\ of RKN chemosensory genes by RNAi soaking.}

Oligonucleotides were designed to amplify the distinct regions (i.e., conserved domains) of selected $M$. incognita chemosensory genes. dsRNAs were synthesized for Mi-odr-1 (766 bp), Mi-odr3 (524 bp), Mi-tax-2 (402 bp), and Mi-tax-4 (926 bp) from the cDNAs of $M$. incognita J2, using the T7 MEGAscript kit (Ambion), following the experimental technique described previously (Shivakumara et al. 2016). dsRNA of an unrelated gene ( $g f p$; GenBank: HF675000) was used as nonnative negative control. Approximately 500 preparasitic J2s were soaked (in triplicate) in a $0.1 \mathrm{mg} / \mathrm{ml}$ solution of target dsRNA in $50 \mu \mathrm{l}$ of soaking buffer (Urwin et al. 2002), for $24 \mathrm{~h}$, in the dark, on a slowly moving rotator. FITC at $0.1 \mathrm{mg} / \mathrm{ml}$ was added separately in the soaking solution in some of the replicates to trace the efficacy of dsRNA uptake by nematodes (Dutta et al. 2016). J2s incubated in dsGFP and in soaking buffer (without dsRNA) served as the control. After incubation and washing with sterile water, RNA was extracted from $\mathrm{J} 2 \mathrm{~s}$ and was reverse-transcribed to cDNA. In order to assess the transcript knockdown of target genes, qRT-PCR was performed.

\section{Infectivity assay.}

Post-RNAi phenotype analysis was done via infectivity and chemotaxis assay. The infectivity assay was carried out in
PF-127 medium (Dash et al. 2017) in which differential attraction to and penetration of host root (tomato cv. Pusa Ruby) by dsRNA-treated J2s (in comparison with control) were investigated. Approximately $100 \mathrm{~J} 2 \mathrm{~s}$ were inoculated at $1.5 \mathrm{~cm}$ posterior from the root tip of host plant in 23\% PF-127 medium (Sigma) in a $50 \times 10 \mathrm{~mm}$ Petri dish. J2s touching the root tip were counted under a microscope at 2, 4, 6, 8, 10, 12, 16, and $18 \mathrm{~h}$ postinoculation. Roots were stained with acid fuchsin (Byrd et al. 1983) at 8, 10, 12, 14, 16, and $18 \mathrm{~h}$ postinoculation, and the number of $\mathrm{J} 2 \mathrm{~s}$ that had invaded the host root were counted. In addition, the locomotion behavior of juveniles (in terms of crawling pattern and tracks inscribed by them on PF127 medium) was also assessed under the microscope.

\section{Chemotaxis assay.}

Chemotaxis assay was conducted in a $50 \times 10 \mathrm{~mm}$ Petri plate containing both agar and PF-127 (Shivakumara et al. 2018). Six milliliters of $0.8 \%$ agarose was poured onto the plate, and two parallel lines, each equidistant $1.5 \mathrm{~cm}$ from the center of the plate, were drawn on the outside of the plate. After solidification, the agar was cut along the marked lines and the area between the lines was scooped out, using sterilized forceps, and was replaced with $3 \mathrm{ml}$ of $23 \% \mathrm{PF}-127$ (liquid at $4^{\circ} \mathrm{C}$ ) and was allowed to set at room temperature. A well of $1.5 \mathrm{~mm}$ diameter was made in the agar, on each side of the agar, adjacent to the agar-PF-127 junction for application of test compounds (Fig. 3C). Test chemicals $(5 \mu \mathrm{l})$ were individually applied in one of the wells and diluent was placed in the other. After $40 \mathrm{~min}$, for establishment of chemical gradient, approximately $100 \mathrm{~J} 2 \mathrm{~s}$ in approximately $2 \mu \mathrm{l}$ of water were injected at the center of the plate in PF-127 medium. After 20 min at room temperature, J2s accumulating near the agar-PF-127 boundary at either the odorant or diluent side were pipetted out from the region between the agarose and PF-127 gel and were counted under the microscope. This was possible because the boundary between the PF-127 gel and the agarose had liquefied, trapping the nematodes and allowing easy removal. The chemotaxis index was calculated as the number of $\mathrm{J} 2 \mathrm{~s}$ at the test chemical side minus the number of $\mathrm{J} 2 \mathrm{~s}$ at the diluent side divided by the total number of $\mathrm{J} 2 \mathrm{~s}$ applied, in which the index ranges from 1.0 (perfect attraction) to -1.0 (perfect repulsion) (Bargmann et al. 1993). Both volatile and nonvolatile chemicals as well as host root exudates were tested. All the chemicals were obtained from Sigma-Aldrich. The volatile compounds were dissolved in sterile ethanol $(0.05 \% \mathrm{vol} / \mathrm{vol})$ and were screened at six different dilutions $\left(10^{0}, 10^{-1}, 10^{-2}, 10^{-3}, 10^{-4}\right.$, and $\left.10^{-5}\right)$ in water. Concentrations of nonvolatile compounds are stated in figure legends. Root exudates of different host plants were collected from seedlings hydroponically grown in Hoagland solution and concentrated to $5 \mathrm{ml}$ of suspension (from $50 \mathrm{ml}$ of initial volume for each host) via vacuum evaporation, using a standard method (Čepulyte et al. 2018). All the experiments were carried out with at least three technical and three biological replicates.

Chemotactic response of dsRNA-treated J2s (compared with control worms) against synthetic ascarosides was performed in PF-127 medium in a $30 \times 10 \mathrm{~mm}$ Petri plate. Ascarosides ascr\#9 (Srinivasan et al. 2012) and ascr\#18 (Manosalva et al. 2015) were synthesized as previously described. Different amounts of ascr\#9 and ascr\#18 were pipetted at a distance of $1 \mathrm{~cm}$ from the center of the assay plate (sterile water was put at the opposite end, $1 \mathrm{~cm}$ distant from center). After allowing $20 \mathrm{~min}$ for gradient establishment, $100 \mathrm{~J} 2 \mathrm{~s}$ (in $2 \mu \mathrm{l}$ of water) were injected into the PF-127 gel at the center. After another $20 \mathrm{~min}$ at room temperature, the number of nematodes that moved toward test compounds or water was counted under the microscope. The chemotaxis index was calculated as described above. 
The bioassay for monitoring nematode head and stylet movement in dsRNA-treated J2s was adapted from methodology described earlier (Dutta et al. 2012). Approximately $50 \mathrm{~J} 2 \mathrm{~s}$ in $2 \mu \mathrm{l}$ of water were incubated with $10 \mu \mathrm{l}$ of tomato root exudate, sterile water (as control), and $0.1 \%$ resorcinol neurotransmitter (as positive control), separately in microcentrifuge tubes, in triplicate. Additionally, $10 \mu \mathrm{l}$ of $0.2 \%$ (wt/vol) Coomassie Brilliant Blue R250 was added to selected tubes to evaluate the nematode stylet secretion. Observations on the frequency of head and stylet movement per minute and formation of blue stains around the stylet were made under the microscope at indicated timepoints.

In order to assess the transcript abundance of $\mathrm{Mi}$-odr-1, $\mathrm{Mi}$ $o d r-3, M i$-tax-2, and Mi-tax-4 in RKN while exposed to host root exudates, 1,000 freshly hatched $\mathrm{J} 2 \mathrm{~s}$ were incubated for $24 \mathrm{~h}$ in $1 \mathrm{ml}$ of exudates of indicated host roots. After washing with sterile water, RNA was extracted from $\mathrm{J} 2 \mathrm{~s}$, was reversetranscribed to cDNA, and qRT-PCR was performed (as described above) for three biological and three technical replicates.

\section{Statistical analysis.}

Data were initially checked for normality and compared using one-way analysis of variance with Tukey's honestly significant difference tests in SAS statistical package. Statistical comparisons were made between different treatments or compared individually to controls, as stated in the figure legends.

\section{ACKNOWLEDGMENTS}

We acknowledge S. Saha (Agricultural Chemicals Division, ICARIARI) for providing some of the test compounds for the present study. We thank V. Phani (Nematology Division, ICAR-IARI) for constructing the phylogenetic trees. Ph.D. student T. N. Shivakumara acknowledges his coguide V. Raina, School of Biotechnology, KIIT, Bhubaneswar, India.

\section{LITERATURE CITED}

Abad, P., Gouzy, J., Aury, J. M., Castagnone-Sereno, P., Danchin, E. G., Deleury, E., Perfus-Barbeoch, L., Anthouard, V., Artiguenave, F., Blok, V. C., Caillaud, M. C., Coutinho, P. M., Dasilva, C., De Luca, F., Deau, F., Esquibet, M., Flutre, T., Goldstone, J. V., Hamamouch, N., Hewezi, T., Jaillon, O., Jubin, C., Leonetti, P., Magliano, M., Maier, T. R., Markov, G. V., McVeigh, P., Pesole, G., Poulain, J., Robinson-Rechavi, M., Sallet, E., Ségurens, B., Steinbach, D., Tytgat, T., Ugarte, E., van Ghelder, C., Veronico, P., Baum, T. J., Blaxter, M., Bleve-Zacheo, T., Davis, E. L., Ewbank, J. J., Favery, B., Grenier, E., Henrissat, B., Jones, J. T., Laudet, V., Maule, A. G., Quesneville, H., Rosso, M. N., Schiex, T., Smant, G., Weissenbach, J., and Wincker, P. 2008. Genome sequence of the metazoan plant-parasitic nematode Meloidogyne incognita. Nat. Biotechnol. 26:909-915.

Bacilio-Jiménez, M., Aguilar-Flores, S., Ventura-Zapata, E., PérezCampos, E., Bouquelet, S., and Zenteno, E. 2003. Chemical characterization of root exudates from rice (Oryza sativa) and their effects on the chemotactic response of endophytic bacteria. Plant Soil 249:271-277.

Bakhetia, M., Urwin, P. E., and Atkinson, H. J. 2008. Characterisation by RNAi of pioneer genes expressed in the dorsal pharyngeal gland cell of Heterodera glycines and the effects of combinatorial RNAi. Int. J. Parasitol. 38:1589-1597.

Bargmann, C. I., Hartwieg, E., and Horvitz, H. R. 1993. Odorant-selective genes and neurons mediate olfaction in C. elegans. Cell 74:515-527.

Bargmann, C. I., and Mori, I. 1997. Chemotaxis and thermotaxis. Pages 717-737 in: C. elegans. D. L. Riddle, T. Blumenthal, B. J. Meyer, and J. R. Priess, eds. Vol. II. Cold Spring Harbor Laboratory Press, Cold Spring Harbor, NY.

Bellafiore, S., Shen, Z., Rosso, M. N., Abad, P., Shih, P., and Briggs, S. P. 2008. Direct identification of the Meloidogyne incognita secretome reveals proteins with host cell reprogramming potential. PLoS Pathog. 4: e1000192.

Blanc-Mathieu, R., Perfus-Barbeoch, L., Aury, J. M., Da Rocha, M., Gouzy, J., Sallet, E., Martin-Jimenez, C., Bailly-Bechet, M., Castagnone-
Sereno, P., Flot, J. F., Kozlowski, D. K., Cazareth, J., Couloux, A., Da Silva, C., Guy, J., Kim-Jo, Y. J., Rancurel, C., Schiex, T., Abad, P., Wincker, P., and Danchin, E. G. J. 2017. Hybridization and polyploidy enable genomic plasticity without sex in the most devastating plantparasitic nematodes. PLoS Genet. 13:e1006777.

Byrd, D. W., Kirkpatrick, T., and Barker, K. R. 1983. An improved technique for clearing and staining plant tissues for detection of nematodes. J. Nematol. 15:142-143.

Čepulyte, R., Danquah, W. B., Bruening, G., and Williamson, V. M. 2018. Potent attractant for root-knot nematodes in exudates from seedling root tips of two host species. Sci. Rep. 8:10847.

Choe, A., von Reuss, S. H., Kogan, D., Gasser, R. B., Platzer, E. G., Schroeder, F. C., and Sternberg, P. W. 2012. Ascaroside signaling is widely conserved among nematodes. Curr. Biol. 22:772-780.

Coburn, C. M., and Bargmann, C. I. 1996. A putative cyclic nucleotidegated channel is required for sensory development and function in C. elegans. Neuron 17:695-706.

Coburn, C. M., Mori, I., Ohshima, Y., and Bargmann, C. I. 1998. A cyclic nucleotide-gated channel inhibits sensory axon outgrowth in larval and adult Caenorhabditis elegans: A distinct pathway for maintenance of sensory axon structure. Development 125:249-258.

Colbert, H. A., and Bargmann, C. I. 1995. Odorant-specific adaptation pathways generate olfactory plasticity in C. elegans. Neuron 14:803-812.

Curtis, R. H. C. 2008. Plant-nematode interactions: Environmental signals detected by the nematode's chemosensory organs control changes in the surface cuticle and behaviour. Parasite 15:310-316.

Dalzell, J. J., McMaster, S., Johnston, M. J., Kerr, R., Fleming, C. C., and Maule, A. G. 2009. Non-nematode-derived double-stranded RNAs induce profound phenotypic changes in Meloidogyne incognita and Globodera pallida infective juveniles. Int. J. Parasitol. 39:1503-1516.

Dash, M., Dutta, T. K., Phani, V., Papolu, P. K., Shivakumara, T. N., and Rao, U. 2017. RNAi-mediated disruption of neuropeptide genes, $n l p-3$ and nlp-12, cause multiple behavioral defects in Meloidogyne incognita. Biochem. Biophys. Res. Commun. 490:933-940.

Dutta, T. K., Banakar, P., and Rao, U. 2015. The status of RNAi-based transgenic research in plant nematology. Front. Microbiol. 5:760.

Dutta, T. K., Banakar, P., and Rao, U. 2016. Standardization of an in vitro feeding protocol for rice root-knot nematode, Meloidogyne graminicola. Int. J. Nematol. 46:73-74.

Dutta, T. K., Powers, S. J., Gaur, H. S., Birkett, M., and Curtis, R. H. 2012 Effect of small lipophilic molecules in tomato and rice root exudates on the behaviour of Meloidogyne incognita and M. graminicola. Nematology 14:309-320.

Dutta, T. K., Powers, S. J., Kerry, B. R., Gaur, H. S., and Curtis, R. H. C. 2011. Comparison of host recognition, invasion, development and reproduction of Meloidogyne graminicola and $M$. incognita on rice and tomato. Nematology 13:509-520.

Elling, A. A. 2013. Major emerging problems with minor meloidogyne species. Phytopathology 103:1092-1102.

Fleming, T. R., Maule, A. G., and Fleming, C. C. 2017. Chemosensory responses of plant parasitic nematodes to selected phytochemicals revea long-term habituation traits. J. Nematol. 49:462-471.

Grundler, F., Schnibbe, L., and Wyss, U. 1991. In vitro studies on behaviour of second-stage juveniles Heterodera schachtii (nematode, Heteroderidae) in response to plant-roots exudates. Parasitology 103:149-155.

Hilliard, M. A., Bargmann, C. I., and Bazzicalupo, P. 2002. C. elegans responds to chemical repellents by integrating sensory inputs from the head and the tail. Curr. Biol. 12:730-734.

Hooks, C. R. R., Wang, K. H., Ploeg, A., and McSorley, R. 2010. Using marigold (Tagetes spp.) as a cover crop to protect crops from plan parasitic nematodes. Appl. Soil Ecol. 46:307-320.

Jones, J. T., Haegeman, A., Danchin, E. G. J., Gaur, H. S., Helder, J., Jones, M. G. K., Kikuchi, T., Manzanilla-López, R., Palomares-Rius, J. E. Wesemael, W. M., and Perry, R. N. 2013. Top 10 plant-parasitic nematodes in molecular plant pathology. Mol. Plant Pathol. 14:946-961.

Kikuchi, T., Eves-van den Akker, S., and Jones, J. T. 2017. Genome evolution of plant-parasitic nematodes. Annu. Rev. Phytopathol. 55:333-354.

Kimber, M. J., Fleming, C. C., Prior, A., Jones, J. T., Halton, D. W., and Maule, A. G. 2002. Localisation of Globodera pallida FMRFamiderelated peptide encoding genes using in situ hybridisation. Int. J. Parasitol. 32:1095-1105.

Komatsu, H., Mori, I., Rhee, J. S., Akaike, N., and Ohshima, Y. 1996. Mutations in a cyclic nucleotide-gated channel lead to abnormal thermosensation and chemosensation in C. elegans. Neuron 17:707-718

Kravchenko, L. V., Azarova, T. S., Leonova-Erko, E. I., Shaposhnikov, A. I., Makarova, N. M., and Tikhonovich, I. A. 2003. Root exudates of tomato plants and their effect on the growth and antifungal activity of Pseudomonas strains. Microbiology 72:37-41. 
Kumari, C., Dutta, T. K., Chaudhary, S., Banakar, P., Papolu, P. K., and Rao, U. 2017. Molecular characterization of FMRFamide-like peptides in Meloidogyne graminicola and analysis of their knockdown effect on nematode infectivity. Gene 619:50-60.

L'Etoile, N. D., and Bargmann, C. I. 2000. Olfaction and odor discrimination are mediated by the $C$. elegans guanylyl cyclase ODR1. Neuron 25:575-586.

Lans, H., Rademakers, S., and Jansen, G. 2004. A network of stimulatory and inhibitory $\mathrm{G} \alpha$-subunits regulates olfaction in Caenorhabditis elegans. Genetics 167:1677-1687.

Lilley, C. J., Davies, L. J., and Urwin, P. E. 2012. RNA interference in plant parasitic nematodes: A summary of the current status. Parasitology 139: 630-640.

Livak, K. J., and Schmittgen, T. D. 2001. Analysis of relative gene expression data using real-time quantitative PCR and the $2^{-\Delta \Delta C(T)}$ method. Methods 25:402-408.

Lu, M., Tian, X., Yang, X., Yuan, C., Ehsan, M., Liu, X., Yan, R., Xu, L., Song, X., and Li, X. 2017. The N- and C-terminal carbohydrate recognition domains of Haemonchus contortus galectin bind to distinct receptors of goat PBMC and contribute differently to its immunomodulatory functions in host-parasite interactions. Parasit. Vectors 10:409.

Ludewig, A. H., and Schroeder, F. C. 2013. Ascaroside signaling in C. elegans. Pages 1-22 in: WormBook: The Online Review of C. elegans Biology. NCBI, Bethesda, MD, U.S.A.

Manosalva, P., Manohar, M., von Reuss, S. H., Chen, S., Koch, A., Kaplan, F., Choe, A., Micikas, R. J., Wang, X., Kogel, K. H., Sternberg, P. W., Williamson, V. M., Schroeder, F. C., and Klessig, D. F. 2015. Conserved nematode signalling molecules elicit plant defenses and pathogen resistance. Nat. Commun. 6:7795.

Moens, M., Perry, R. N., and Starr, J. L. 2009. Meloidogyne species - a diverse group of novel and important plant parasites. Pages 1-17 in: Root-knot nematodes. R. N. Perry, M. Moens, and J. L. Starr, eds. CAB International Publishers, Wallingford, UK.

Naito, Y., Yamada, T., Matsumiya, T., Ui-Tei, K., Saigo, K., and Morishita, S. 2005. dsCheck: Highly sensitive off-target search software for doublestranded RNA-mediated RNA interference. Nucleic Acids Res. 33: W589-W591.

Palomares-Rius, J. E., Escobar, C., Cabrera, J., Vovlas, A., and Castillo, P. 2017. Anatomical alterations in plant tissues induced by plant-parasitic nematodes. Front. Plant Sci. 8:1987.

Perry, R. N. 1996. Chemoreception in plant parasitic nematodes. Annu. Rev. Phytopathol. 34:181-199.

Perry, R. N. 2005. An evaluation of types of attractants enabling plantparasitic nematodes to locate plant roots. Russ. J. Nematol. 13:83-88.

Posada, D., and Crandall, K. A. 1998. MODELTEST: Testing the model of DNA substitution. Bioinformatics 14:817-818.

Rengarajan, S., and Hallem, E. A. 2016. Olfactory circuits and behaviors of nematodes. Curr. Opin. Neurobiol. 41:136-148.

Reynolds, A. M., Dutta, T. K., Curtis, R. H. C., Powers, S. J., Gaur, H. S., and Kerry, B. R. 2011. Chemotaxis can take plant-parasitic nematodes to the source of a chemo-attractant via the shortest possible routes. J. R. Soc. Interface 8:568-577.

Roayaie, K., Crump, J. G., Sagasti, A., and Bargmann, C. I. 1998. The Go protein ODR-3 mediates olfactory and nociceptive function and controls cilium morphogenesis in C. elegans olfactory neurons. Neuron 20:55-67.

Rosso, M.-N., Jones, J. T., and Abad, P. 2009. RNAi and functional genomics in plant parasitic nematodes. Annu. Rev. Phytopathol. 47:207-232.

Sengupta, P., Chou, J. H., and Bargmann, C. I. 1996. odr-10 encodes a seven transmembrane domain olfactory receptor required for responses to the odorant diacetyl. Cell 84:899-909.

Shivakumara, T. N., Chaudhary, S., Kamaraju, D., Dutta, T. K., Papolu, P. K., Banakar, P., Sreevathsa, R., Singh, B., Manjaiah, K. M., and Rao, U. 2017. Host-induced silencing of two pharyngeal gland genes conferred transcriptional alteration of cell wall-modifying enzymes of Meloidogyne incognita vis-à-vis perturbed nematode infectivity in eggplant. Front. Plant Sci. 8:473.

Shivakumara, T. N., Dutta, T. K., and Rao, U. 2018. A novel in vitro chemotaxis bioassay to assess the response of Meloidogyne incognita towards various test compounds. J. Nematol. 50:487-494.

Shivakumara, T. N., Papolu, P. K., Dutta, T. K., Kamaraju, D., Chaudhary, S., and Rao, U. 2016. RNAi-induced silencing of an effector confers transcriptional oscillation in another group of effectors in the root-knot nematode, Meloidogyne incognita. Nematology 18:857-870.

Smant, G., Goverse, A., Stokkermans, J. P. W. G., De Boer, J. M., Pomp, H. R., Zilverentant, J. F., Overmars, H. A., Helder, J., Schots, A., and
Bakker, J. 1997. Potato root diffusate-induced secretion of soluble, basic proteins originating from the subventral esophageal glands of potato cyst nematodes. Phytopathology 87:839-845.

Srinivasan, J., von Reuss, S. H., Bose, N., Zaslaver, A., Mahanti, P., Ho, M. C., O’Doherty, O. G., Edison, A. S., Sternberg, P. W., and Schroeder, F. C. 2012. A modular library of small molecule signals regulates social behaviors in Caenorhabditis elegans. PLoS Biol. 10: e1001237.

Szitenberg, A., Salazar-Jaramillo, L., Blok, V. C., Laetsch, D. R., Joseph, S., Williamson, V. M., Blaxter, M. L., and Lunt, D. H. 2017. Comparative genomics of apomictic root-knot nematodes: Hybridization, ploidy, and dynamic genome change. Genome Biol. Evol. 9:2844-2861.

Teillet, A., Dybal, K., Kerry, B. R., Miller, A. J., Curtis, R. H., and Hedden, P. 2013. Transcriptional changes of the root-knot nematode Meloidogyne incognita in response to Arabidopsis thaliana root signals. PLoS One 8: e61259.

Urwin, P. E., Lilley, C. J., and Atkinson, H. J. 2002. Ingestion of doublestranded RNA by preparasitic juvenile cyst nematodes leads to RNA interference. Mol. Plant-Microbe Interact 15:747-752.

von Mende, N. 1997. Invasion and migration behavior of sedentary nematodes. Pages 51-64 in: Cellular and molecular aspects of plantnematode interactions. C. Fenol, F. M. W. Grundler, and S. A. Ohl, eds. Kluwer Academic Publishers, Dordrecht, The Netherlands.

Wang, C. L., Lower, S., and Williamson, V. M. 2009. Application of Pluronic gel to the study of root-knot nematode behaviour. Nematology 11:453-464.

Wang, D., Jones, L. M., Urwin, P. E., and Atkinson, H. J. 2011. A synthetic peptide shows retro- and anterograde neuronal transport before disrupting the chemosensation of plant-pathogenic nematodes. PLoS One 6:e17475.

Whitehead, A. G., and Hemming, J. R. 1965. A comparison of some quantitative methods of extracting small vermiform nematodes from soil. Ann. Appl. Biol. 55:25-38.

Wubben, M. J., 2nd, Su, H., Rodermel, S. R., and Baum, T. J. 2001. Susceptibility to the sugar beet cyst nematode is modulated by ethylene signal transduction in Arabidopsis thaliana. Mol. Plant-Microbe Interact 14:1206-1212.

Wuyts, N., Lognay, G., Verscheure, M., Marlier, M., de Waele, D., and Swennen, R. 2007. Potential physical and chemical barriers to infection by the burrowing nematode Radopholus similis in roots of susceptible and resistant banana (Musa spp.). Plant Pathol. 56: 878-890.

Wuyts, N., Swennen, R., and de Waele, D. 2006. Effects of plant phenylpropanoid pathway products and selected terpenoids and alkaloids on the behavior of the plant-parasitic nematodes Radopholus similis, Pratylenchus penetrans and Meloidogyne incognita. Nematology 8:89-101.

Yan, Y., and Davis, E. L. 2002. Characterisation of guanylyl cyclase genes in the soybean cyst nematode, Heterodera glycines. Int. J. Parasitol. 32: 65-72.

Yu, S., Avery, L., Baude, E., and Garbers, D. L. 1997. Guanylyl cyclase expression in specific sensory neurons: A new family of chemosensory receptors. Proc. Natl. Acad. Sci. U.S.A. 94:3384-3387.

Zhang, Y., Lu, H., and Bargmann, C. I. 2005. Pathogenic bacteria induce aversive olfactory learning in Caenorhabditis elegans. Nature 438: 179-184.

Zhao, X., Schmitt, M., and Hawes, M. C. 2000. Species-dependent effects of border cell and root tip exudates on nematode behavior. Phytopathology 90:1239-1245.

Zuckerman, B. M., and Jansson, H. 1984. Nematode chemotaxis and possible mechanisms of host/prey recognition. Annu. Rev. Phytopathol. 22:95-113.

\section{AUTHOR-RECOMMENDED INTERNET RESOURCES}

ExPASy SIB Bioinformatics Resource portal: https://www.expasy.org InterProScan: https://www.ebi.ac.uk/interpro Meloidogyne Genomic Resource database: https://www6.inra.fr/meloidogyne_incognita Motif database: http://molbiol-tools.ca/Motifs.htm MultAlin: http://multalin.toulouse.inra.fr/multalin SMART database: http://smart.embl-heidelberg.de Wormbase Parasite BLAST search page:

https://parasite.wormbase.org/Tools/Blast 